\title{
A Systematic Review on Exercise Addiction and the Disordered Eating-Eating Disorders Continuum in the Competitive Sport Context
}

\author{
Débora Godoy-Izquierdo $^{1,2}$ (D) María J. Ramírez ${ }^{2}$ - Isabel Díaz ${ }^{3} \cdot$ Clara López-Mora $^{4}$
}

Accepted: 24 July 2021 /Published online: 30 August 2021

(C) The Author(s) 2021, corrected publication 2021

\begin{abstract}
Exercise addiction (EA) affects a considerable number of individuals who regularly perform exercise-sport activities. The co-occurrence of EA manifestations and the continuum of disordered eating-eating disorders (EDs) is so common in sports that a deeper understanding of them as comorbidities is warranted. The aim of this review is to provide an up-to-date overview and synthesis of the research on the relationship between maladaptive exercise and dysfunctional eating in the sport context. A systematic review was conducted following the PRISMA guidelines. A total of 22 empirical studies (23 articles) with young and adult female and male athletes from several sports and competition levels was included. EA in conjunction with eating disturbances is frequent among athletes, yet the prevalence rates are inconsistent. Existing evidence suggests that EA is a relevant outcome of ED pathology among athletes, supporting the classical secondary type of EA. However, research also reveals that excessive exercising plays a central role in the psychopathology of disordered eating. There is a need for further quantitative research addressing the features and correlates of the EA-EDs dyad, qualitative research on the subjective experiences of athletes with disordered exercise and eating, longitudinal and experimental research to establish possible causal paths and attempts to develop comprehensive conceptual models of EA and its co-occurrence with EDs, in order to improve the identification, prevention, and management of this dyadic condition in the sport context.
\end{abstract}

Keywords Exercise addiction · Exercise dependence $\cdot$ Maladaptive exercise $\cdot$ Unhealthy eating $\cdot$ Eating disorders $\cdot$ Athletes

Débora Godoy-Izquierdo deborag@ugr.es

Extended author information available on the last page of the article 


\section{Introduction}

In the last decades, the scientific community has described unhealthy, even pathological, forms of exercise and athletic physical practice. This problematic exercise is easily observable, for example, in subgroups of regular exercisers who attend gyms, practitioners, and athletes in some exercise-sport activities such as weightlifting/bodybuilding or long-distance running and combined endurance modalities (e.g., duathlon, triathlon, ironman) as well as in individuals with eating disorders (EDs), body image disorders (e.g., muscle dysmorphic disorder), or other psychopathologies (e.g., addiction disorders).

Most experts agree that maladaptive, abusive exercising is a multidimensional phenomenon involving unique qualitative features regarding the relevance conceded to the activity (i.e., attitudes toward exercise or training, obsessive aspects, preoccupation), control of the behavior (i.e., loss of control, compulsion, drive or compelling aspects, rigidity), conditions of the practice (e.g., even when fatigue, illness or injury is present), centrality of the behavior (e.g., priority, interferences with personal and social life, conflicts with responsibilities), harmful consequences (e.g., exhaustion, illness, injury, subjective ill-being, social conflict), and withdrawal symptoms (e.g., negative mood when exercise is impeded, guilt when a training session is missed), rather than exclusively quantitative features of excessive volume (i.e., type, duration, frequency and intensity of physical activity) which can hardly be judged as pathologic without considering, among other factors, the individuals' physical condition, health status, age, and regular level of training (e.g., Adams 2009; Adams and Kirkby 1998; Allegre et al. 2006; Berczik et al. 2012; Cook et al. 2014; Davis 2000; De Coverley Veale 1987; Freimuth et al. 2011; Gonçalves et al. 2019; Hausenblas and Symons Downs 2002a; Kerr et al. 2007; Lichtenstein et al. 2017; Petit and Lejoyeux 2013; Szabo 2009; Szabo and Egorov 2015; Szabo et al. 2018; Weinstein and Weinstein 2014).

In addition, a plethora of terms have been used to name this problematic engagement in exercise (e.g., exercise addiction/dependence, obligatory/excessive/abusive/compulsive exercise, exercise misuse/abuse), making the agreement in operationalization and the interpretation of the literature challenging; although each term has its specific features and connotations, it has been proposed that exercise addiction (EA) is preferable, as it includes all the abovementioned meanings (e.g., Berczik et al. 2012; Cook et al. 2014; Freimuth et al. 2011; Hausenblas and Symons Downs 2002a; Lichtenstein et al. 2017; Petit and Lejoyeux 2013; Szabo et al. 2015, 2018; Weinstein and Weinstein 2014). Thus, following this perspective, the affected individual behaves compulsively, exhibits withdrawal symptoms when exercise is not possible, and - due to extreme volumes of exercise - experiences conflict as well as negative life consequences (Szabo et al. 2016). EA has been increasingly investigated in recent decades, although it is still poorly understood, and the debate on the definition, characterization, measurement, and management of this excessive pattern of involvement in physical activity continues.

\section{The Disordered Eating-Eating Disorders Continuum and EA in the Athletic Population}

Currently, the links between excessive exercise and eating pathology are recognized, but they remain quite unclear, particularly among athletes. After early anecdotal research in the sport context, studies on the association between both disturbances have increased in the last decade. The first study relating exercise dependence and EDs in sports was that by Yates et al. (1983), in which obligatory male runners and females suffering from anorexia nervosa were compared 
to show that they shared similar psychological characteristics regarding concerns about food, body weight and fat, rigid eating habits, and exercise compulsion, as well as some personality traits and individual characteristics; the authors postulated that the conditions were analogous and represented different manifestations of the same underlying pathology (Adams 2009). This study initiated other research investigating the so-called anorexia analogue hypothesis, supporting some differences between obligatory and nonobligatory runners in terms of personality traits such as perfectionism and trait anxiety but also concerns about body and weight control (e.g., Le Grange and Eisler 1993; Yates 1991). From then to now, research on EA and its overlap and co-occurrence with other damaging dysfunctional and excessive behaviors, such as disordered eating and EDs, has extended considerably to acknowledge that these twinned phenomena affect not only recreational exercisers but also competitive athletes.

Soon after the paper by Yates et al., De Coverley Veale (1987) discriminated between primary exercise dependence, i.e., exercising is an end in itself, the behavior is intrinsically rewarding and individuals are motivated for the psychological gratification resulting from exercise behavior, so that any effort - including weight control - is used to facilitate additional exercise and athletic performance goals; and secondary exercise dependence, i.e., the individual is driven to exercise to accomplish a separate outcome, as occurs when (s)he exercises to facilitate an eating or body image dysfunction. In the secondary type, exercise is used as a compensatory behavior for losing weight, balancing calories, controlling body composition and enhancing physical appearance, or for regulating weight-related affect (as a means to escape unpleasant affect linked to overconcern about the relationship between exercise and weight control), thus being a symptom of an ED. Consequently, it has been proposed that, instead of having addiction features, secondary exercise manifestations are better recognized by compulsive features (Cook et al. 2014).

Since the very early studies in the sports arena, primary and secondary exercise dependence have proven to be distinct and independent conditions (e.g., Blaydon et al. 2002, 2004; Cook et al. 2013; Cook and Luke 2017; Cunningham et al. 2016). However, the existence of EA as a secondary dependence has been debated (see Adams 2009; Cook et al. 2014; Szabo 2010; Szabo et al. 2015). Others have stated that EA and EDs cannot exist independently from one another at all, so EA is always secondary, a subset or a particular manifestation of an ED (see Adams 2009; Cook et al. 2014; Lichtenstein et al. 2017). Qualitative research on selfnarratives also supports this claim (e.g., Bamber et al. 2000). More radically, it has been affirmed that, in the absence of eating pathology, problematic exercise is not considered to constitute a clinically relevant syndrome (Meyer et al. 2011). As recent reviews on exercise dependence reveal (e.g., Gonçalves et al. 2019), it is at least unmistakable that there exists a commitment to problematic exercise that is clearly related to weight and shape preoccupation, weight control, dietary attitudes and behaviors, and body image issues.

It is this form of EA that is "secondary" to psychopathology and exacerbates symptoms and consequences of eating-related disturbance that capturing our interest. (The term secondary is quoted to emphasize that it suggests a causality between EDs and maladaptive exercise behavior, but, as will be presented in this review, evidence shows a bidirectional intertwining rather than a unidirectional association.)

The forms and features of compulsive exercise in EDs or associated with disordered eating have been increasingly investigated (e.g., Cook et al. 2014; Dalle Grave 2009; Meyer et al. 2011; Meyer and Taranis 2011; Petit and Lejoyeux 2013; Trott et al. 2020b). EDs and EA have many manifestations and symptoms in common, show a high co-occurrence, and are 
comorbid with other related disorders, such as body image disorders. EA is a common feature across EDs, particularly those linked to underweight (Dalle Grave 2009; Meyer et al. 2011). Prevalence rates of up to $80 \%$ indicate that a high number of individuals suffering from an ED such as anorexia, bulimia, binge eating, or not specified eating-related disorders also exhibit unhealthy exercise behavior (Gapin and Petruzzello 2011), with rates notably greater than those found in the general population (e.g., Gümmer et al. 2015; Melissa et al. 2020; Teixeira et al. 2009). The odds of ever being diagnosed with an ED have been found to be more than 2.5 times higher for excessive exercisers compared to individuals with lower activity levels (Kostrzewa et al. 2013). The high percentage of individuals with a pathological form of exercise among those with EDs points to a link between weight and/or shape concerns, dieting and excessive exercise (Zeeck et al. 2017). In EDs, compulsive exercise (i.e., secondary EA) has two main functions (Dalle Grave 2009): (i) to control body shape and weight as a complement or an alternative to other weight-control strategies and (ii) to manage adverse moods, both overall and withdrawal-related negative emotional states. Compulsive exercise is thus a potent maintenance mechanism for EDs (Dalle Grave 2009). In a review, Meyer et al. (2011) identified four key correlates of pathological exercising in individuals with an ED: eating pathology (weight and shape concerns), affect regulation (mood improvement and avoidance of withdrawal symptoms), compulsivity (lack of control, guilt, and perceived negative consequences of stopping), and perfectionism/rigidity.

Nevertheless, it is intuitive that EA could also play a central role in the pathogenesis of disordered eating as an antecedent factor. As research in the context of EDs has evidenced, problematic exercise is a common feature across EDs; the similarities with eating disturbances and the increased EA in association with an ED may explain the augmented prevalence of eating pathology in athletes (Cook et al. 2014). Supporting this path, obligatory exercise or EA attitudes and behaviors, instead of frequency and duration of exercise - has been identified as having an important role in the development and maintenance of eating pathology (Cook and Hausenblas 2008). Problematic exercise has been consistently linked in non-athletes, exercisers, and the general population to body dissatisfaction, drive for thinness, weight preoccupation, more severe presentations of disordered eating, and poorer treatment outcomes, suggesting possible negative consequences of obligatory exercise, alternatively to primary motives for unhealthy, compulsive exercise. Supporting this, reporting exercising solely for weight and shape reasons and intense guilt after postponement or impediment of exercise markedly elevates the risk for eating psychopathology in both regular exercisers and ED patients (e.g., Dalle Grave et al. 2008; Danielsen et al. 2016; Mond et al. 2006; Reche and Gómez 2014; Sauchelli et al. 2016).

Unfortunately, evidence to date does not allow the establishment of causal ordering in the association between EA and disordered eating. There is convincing evidence that EA can be manifested concurrently with an ED, yet the association reported in studies does not represent a directional or causal relationship (Adams 2009).

Research to date has also stated that consequences of EA associated with dysfunctional eating - irrespective of the hen-and-egg question - are far-reaching and highly severe, including earlier ED onset, more eating pathology symptoms, higher dietary restraint, lower body mass index (BMI), greater derived psychopathology such as depression, increased physical health risks including cardiac, metabolic, endocrine, musculoskeletal, and neurologic overuse problems, higher persistence or maintenance of the eating pathology, higher odds of chronicity, lower efficacy of treatments, higher obstruction to weight restoration, longer treatment times and hospital admissions, higher treatment drop-out, and earlier and more frequent relapses (Dalle Grave 2009; Dalle Grave et al. 2008; Meyer et al. 2011). 
EA affects a considerable number of athletes, with estimates ranging from 3 to $77 \%$ (see Godoy-Izquierdo et al., in this Issue for a review), yet inconsistencies and large variability are observed in the research exploring prevalence rates. The EA-EDs dyad is also frequent among athletes, yet discrepancies can be observed in the prevalence rates reported in the literature as well. It has been proposed that comorbid EA and EDs is more prevalent than primary, pure EA (Bär and Markser 2013; Cunningham et al. 2016). It has been estimated that the comorbidity of disordered eating and EA reaches $40 \%$ of the general active population (see Petit and Lejoyeux 2013). Supporting this, in a recent meta-analytic study (Trott et al. 2020b) on the prevalence of EA in adults - including the general population, exercisers, and athletic samples - with and without EDs, it was found that individuals with an ED have more than a 3.5 times higher risk of reporting addiction to exercise. Specifically, it was found that $81 \%$ of individuals scored below the cutoff for eating pathology, of which $20 \%$ had EA; in contrast, of the $19 \%$ of individuals with a possible ED, 55\% reported EA. Notably, the odds ratios differed largely depending on the EA measurement tool, with the Obligatory Exercise Questionnaire demonstrating the highest odds ratio $(\mathrm{OR}=6.9)$, the Exercise Dependence Questionnaire demonstrating the lowest odds ratio $(\mathrm{OR}=2.4)$, and the Exercise Addiction Inventory and the Exercise Dependence Scale showing intermediate values $(\mathrm{OR}=3.9-4.2)$ (see Table 1 for details on the measures).

\section{Aims}

It has been proposed that secondary exercise dependence is far more common than primary exercise dependence (e.g., Trott et al. 2020b). While there are some meta-analyses on EA in athletes (e.g., Di Lodovico et al. 2019; Marques et al. 2019; Nogueira et al. 2018), there is no systematic review on the conjunction of EDs and EA in the sport context, their prevalence, risk factors, prognosis, prevention and treatment, and the phenomenological and subjective experiences facing those suffering from this dyad that is so detrimental for performance and health. Although compulsive exercise might be an evident comorbid companion of disordered eating or a psychopathological component within an ED in exerciser or general population samples or in ED patients, compulsive physical activity can be more covert and less apparent in the athletic population due to naturally occurring higher training volumes, thus hiding its problematic nature within a disturbed exercise and eating pathologic condition and not prompting an early investigation into a potential problem among athletes. Thus, there is a call for a deeper understanding of this reality to help athletes in need.

Consequently, an in-depth literature review was conducted on the association between EA and disordered eating, at all subclinical/clinical levels, in the sport context (competitive athletes). The present review may help health-care professionals assist athletes with psychological issues and mental health disorders by providing an overview of recent developments on the dysfunctional eating and addiction to exercise dyad.

\section{Methods}

\section{Search Strategy, Inclusion Criteria, and Study Selection}

A systematic search was conducted using the electronic databases Web of Science, Scopus, Proquest (including APA PsycArticles, APA PsycExtra, APA PsycInfo, Psychology Database, 


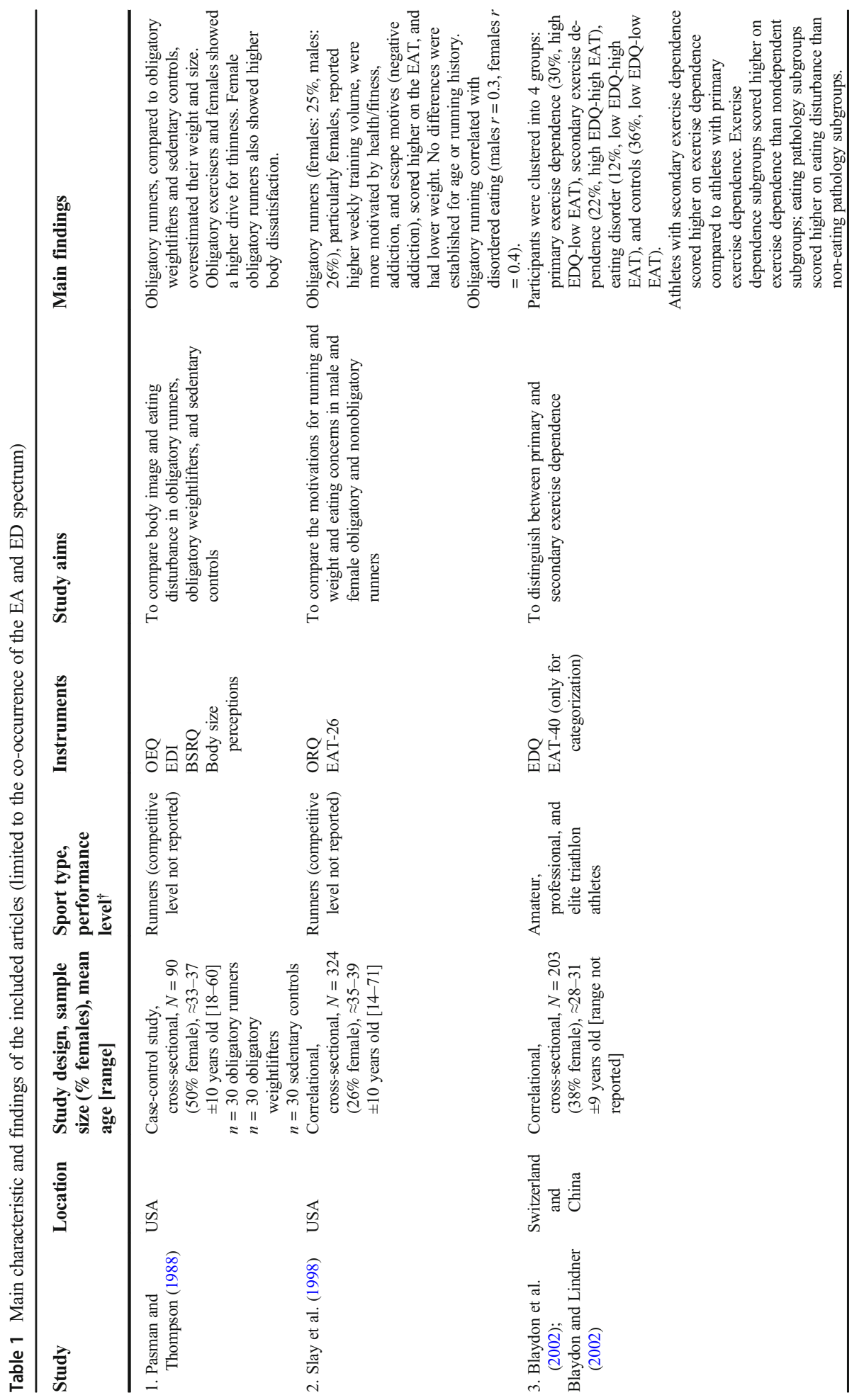




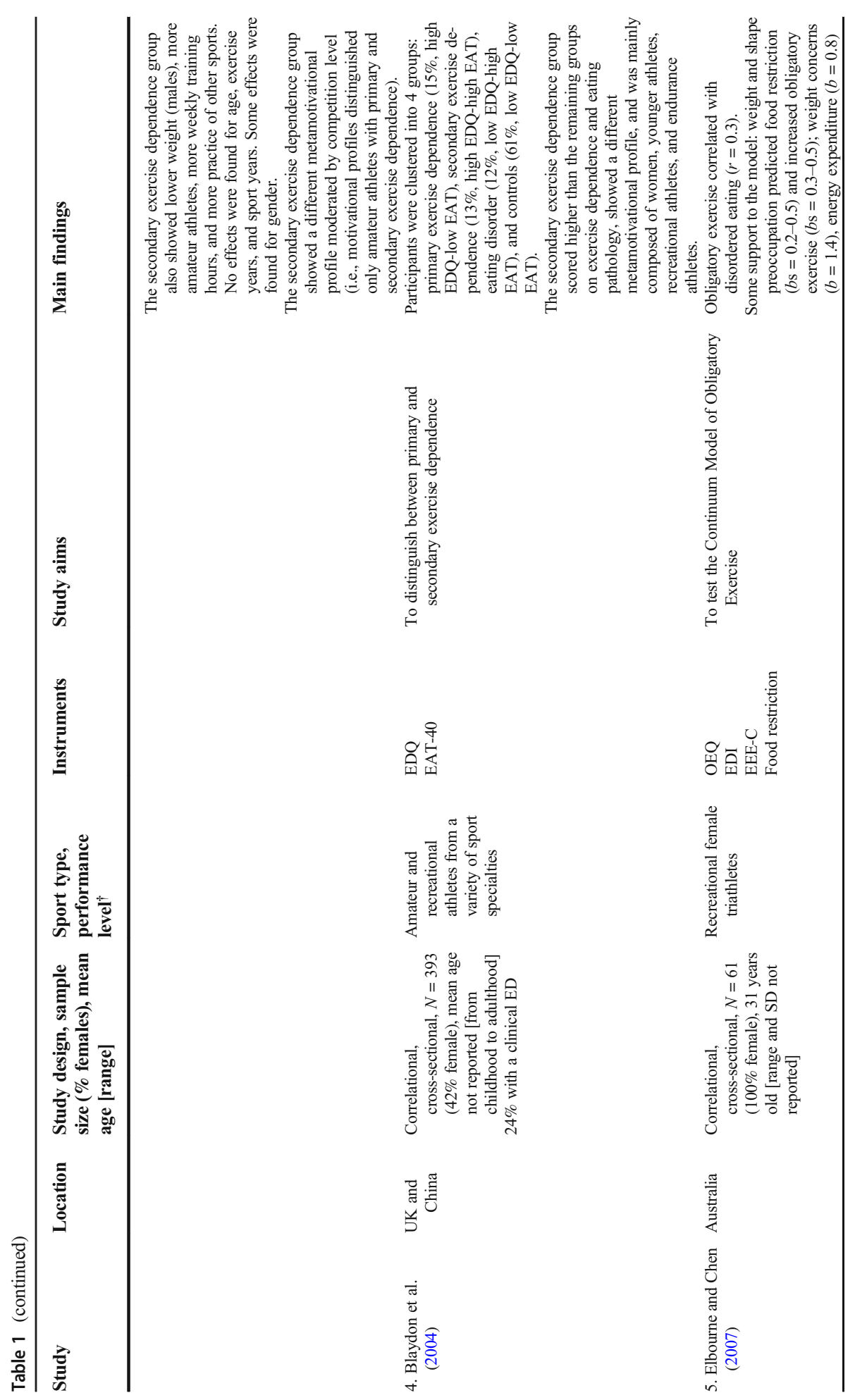




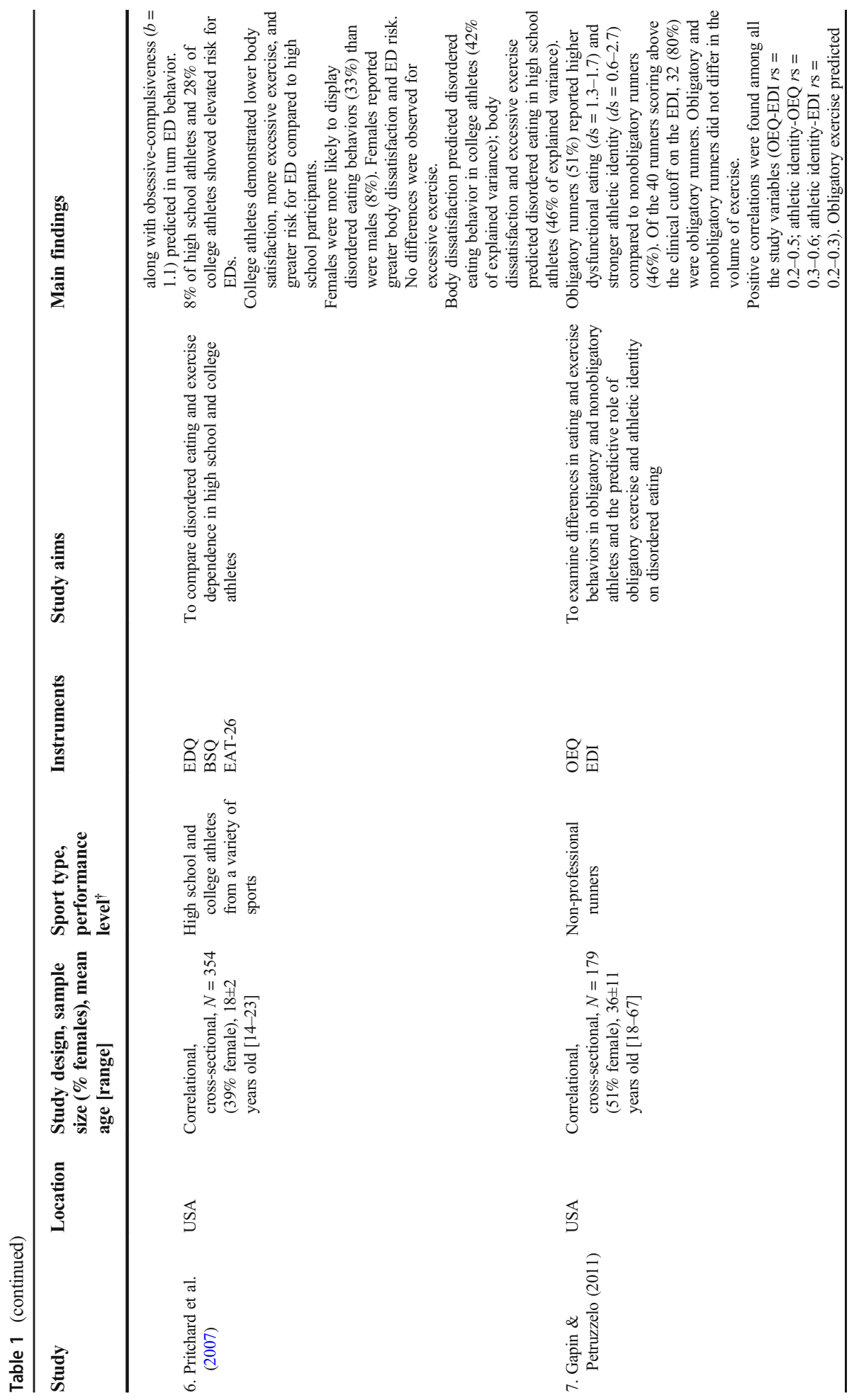




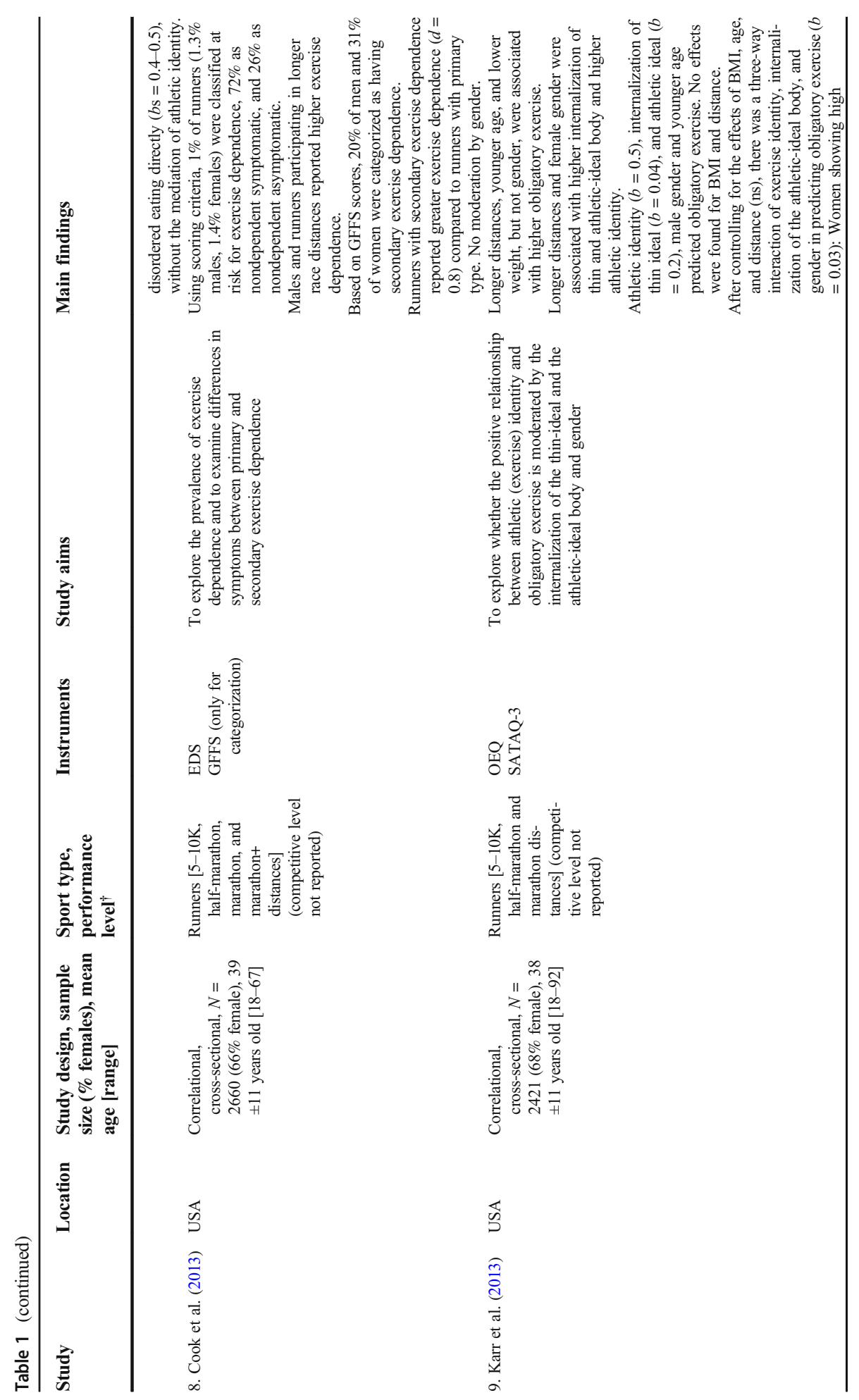




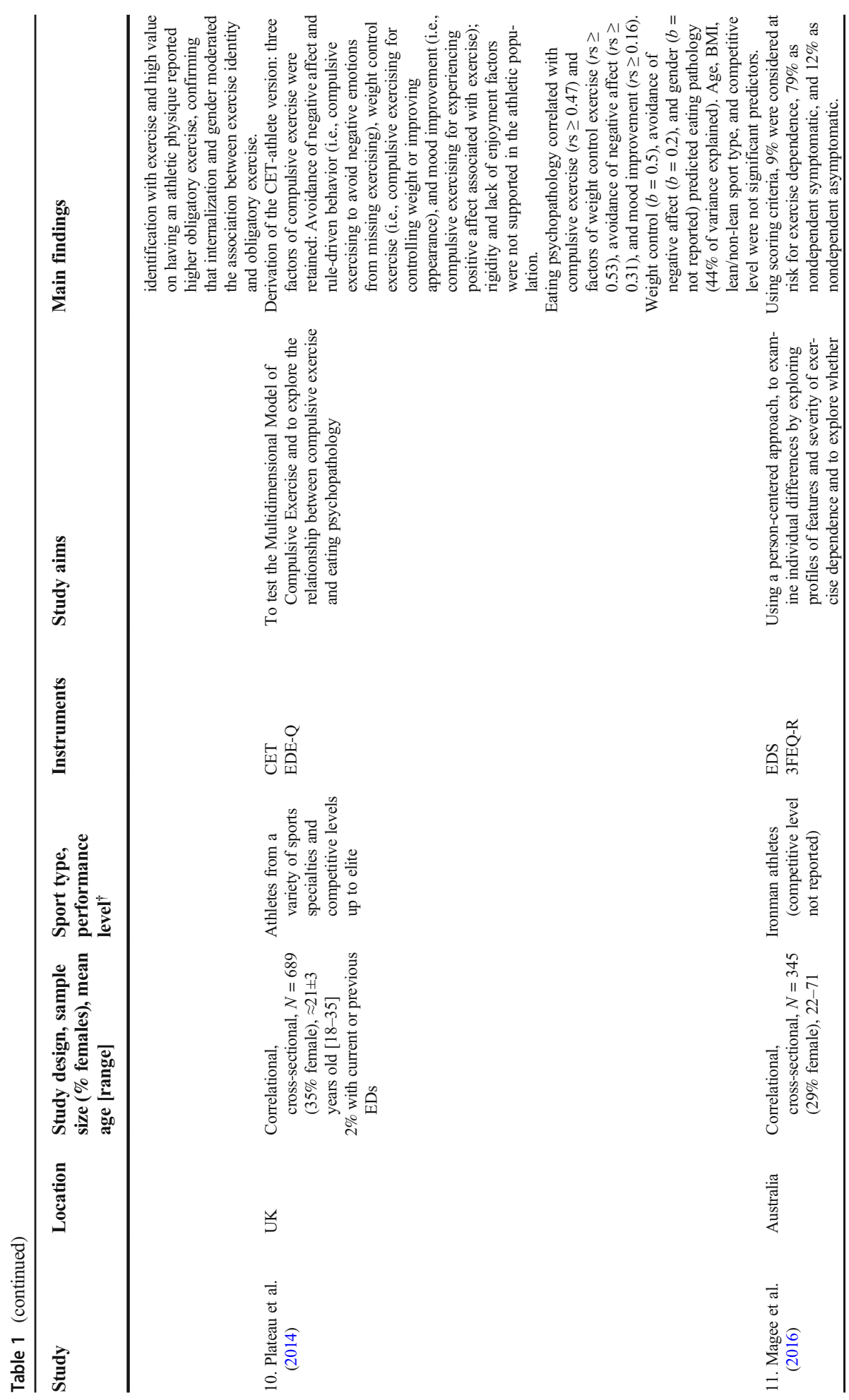




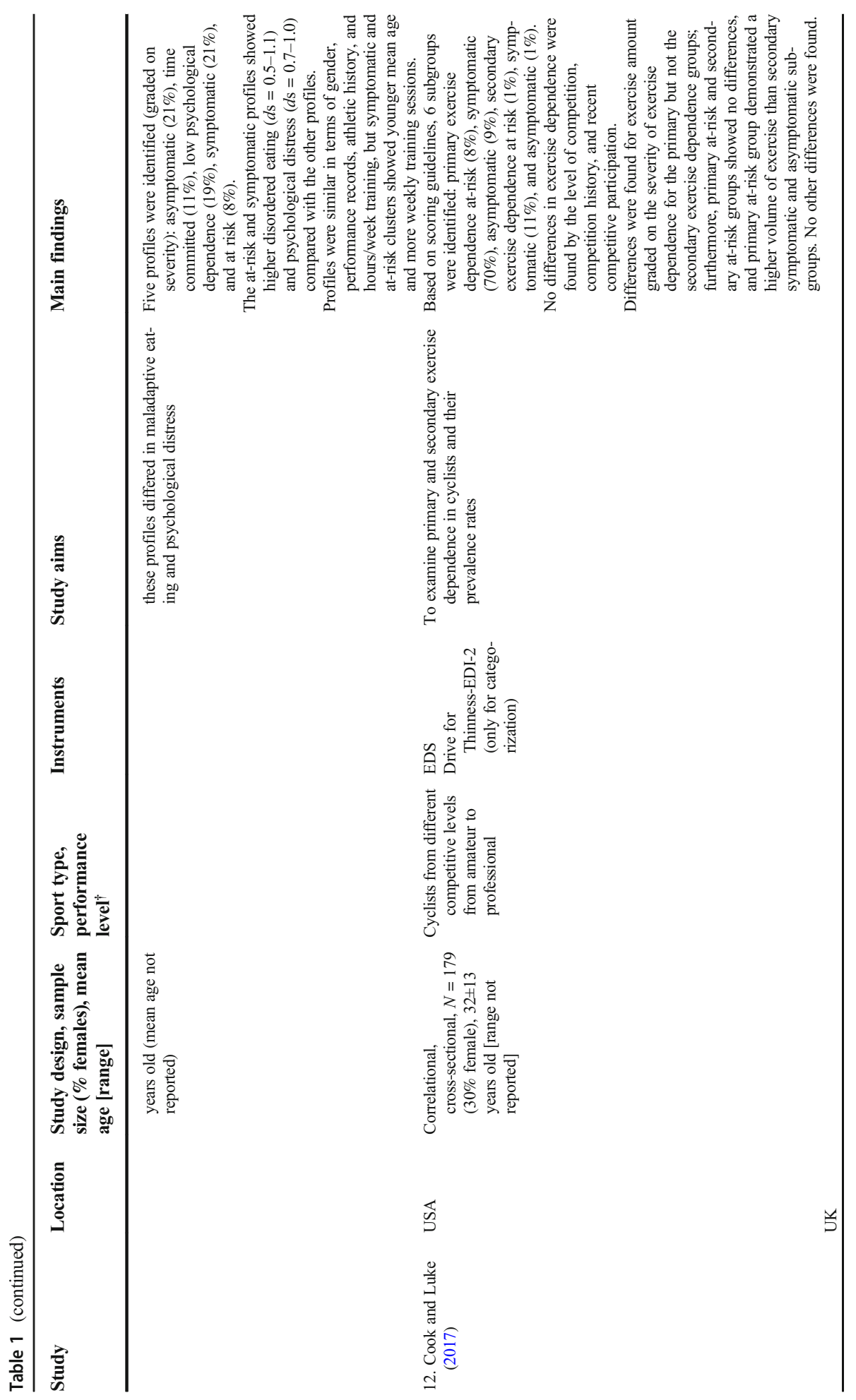




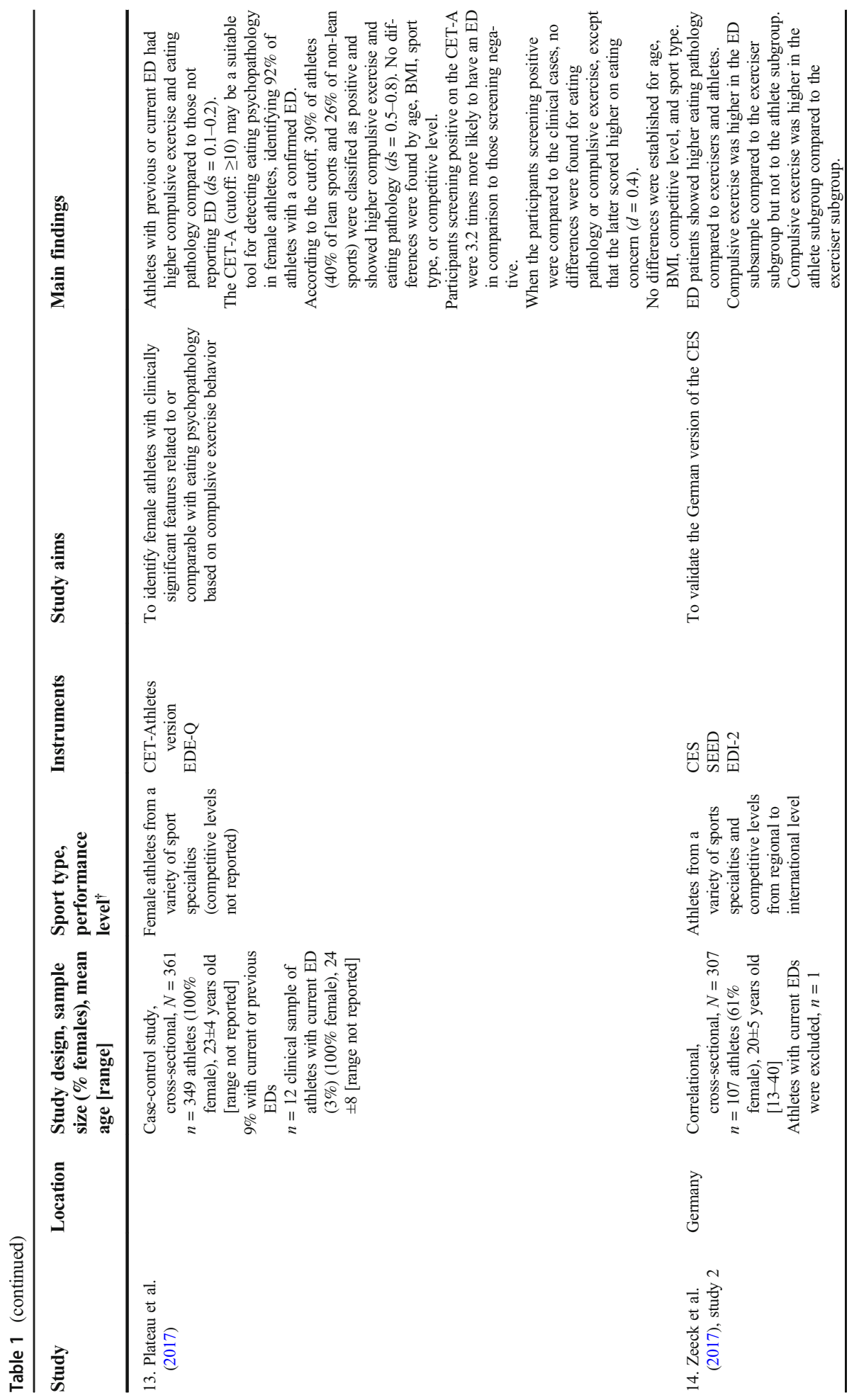




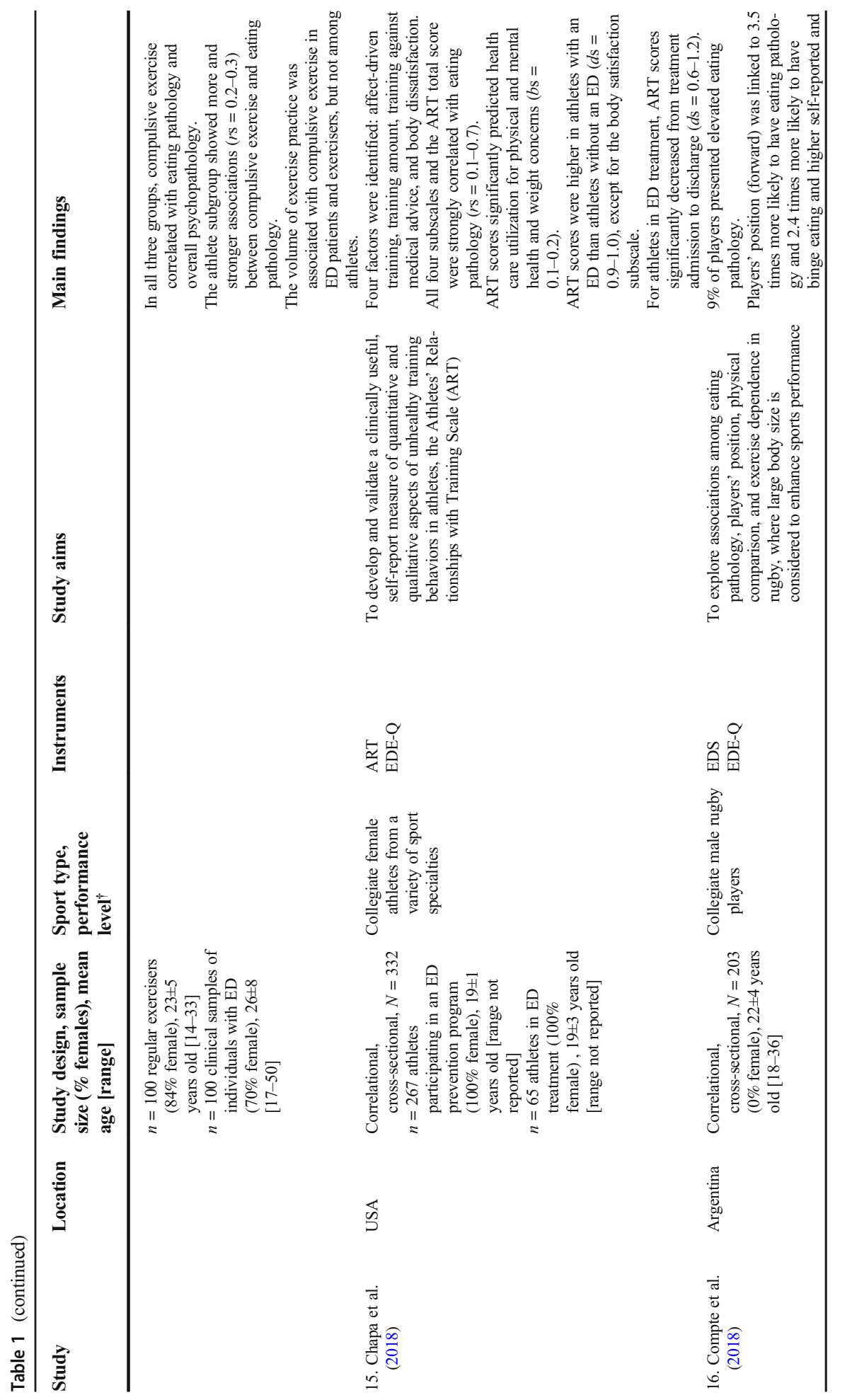




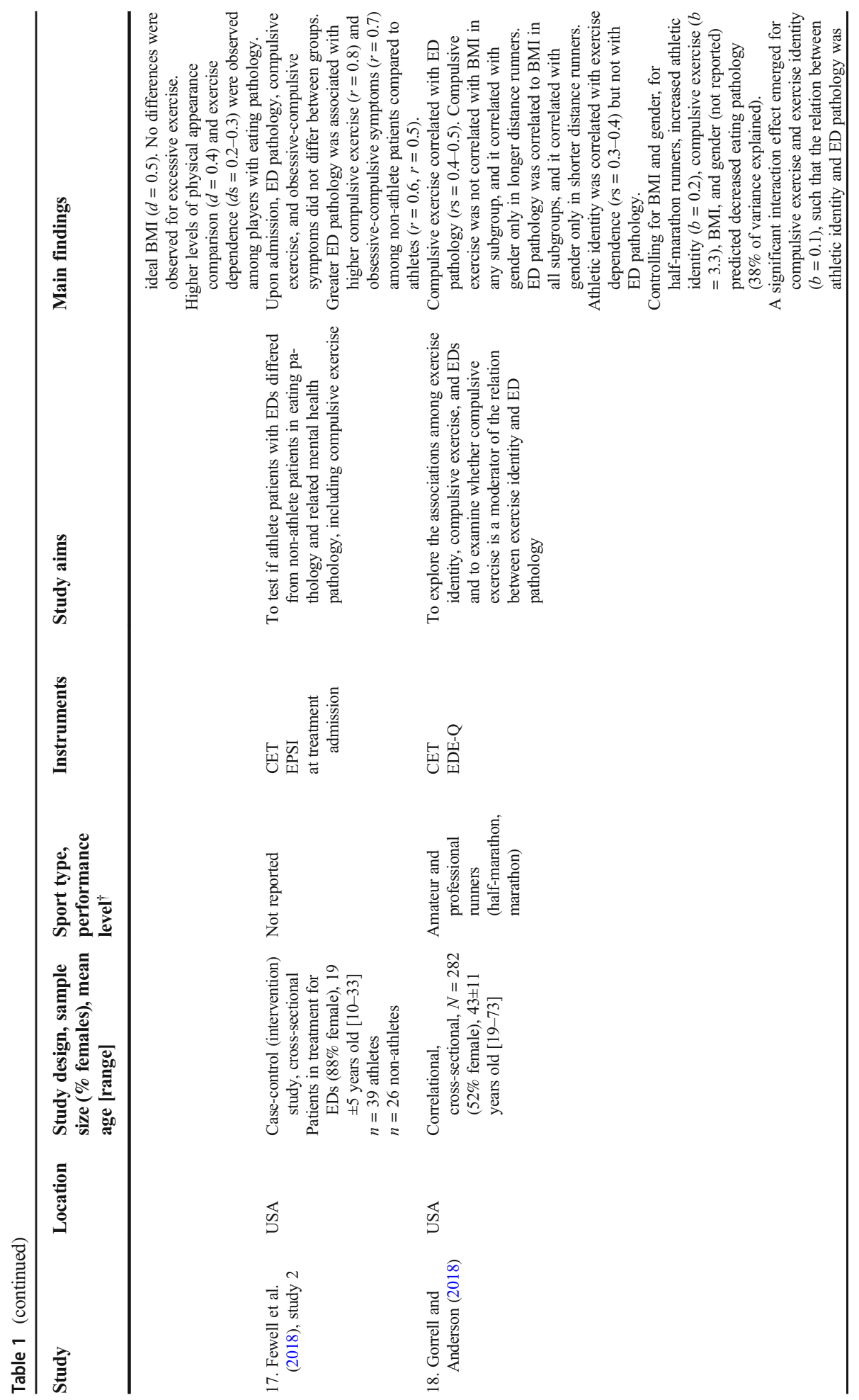




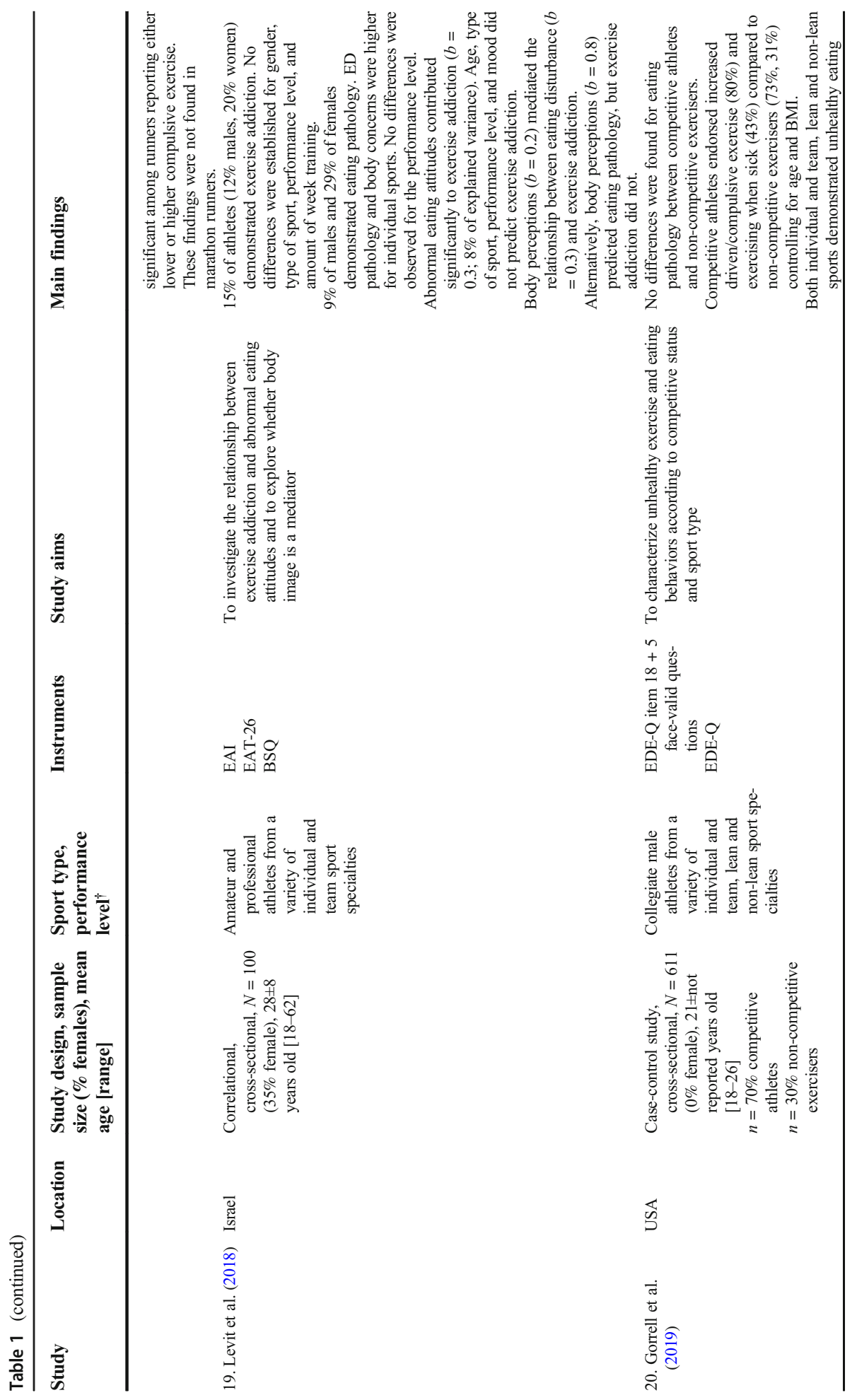




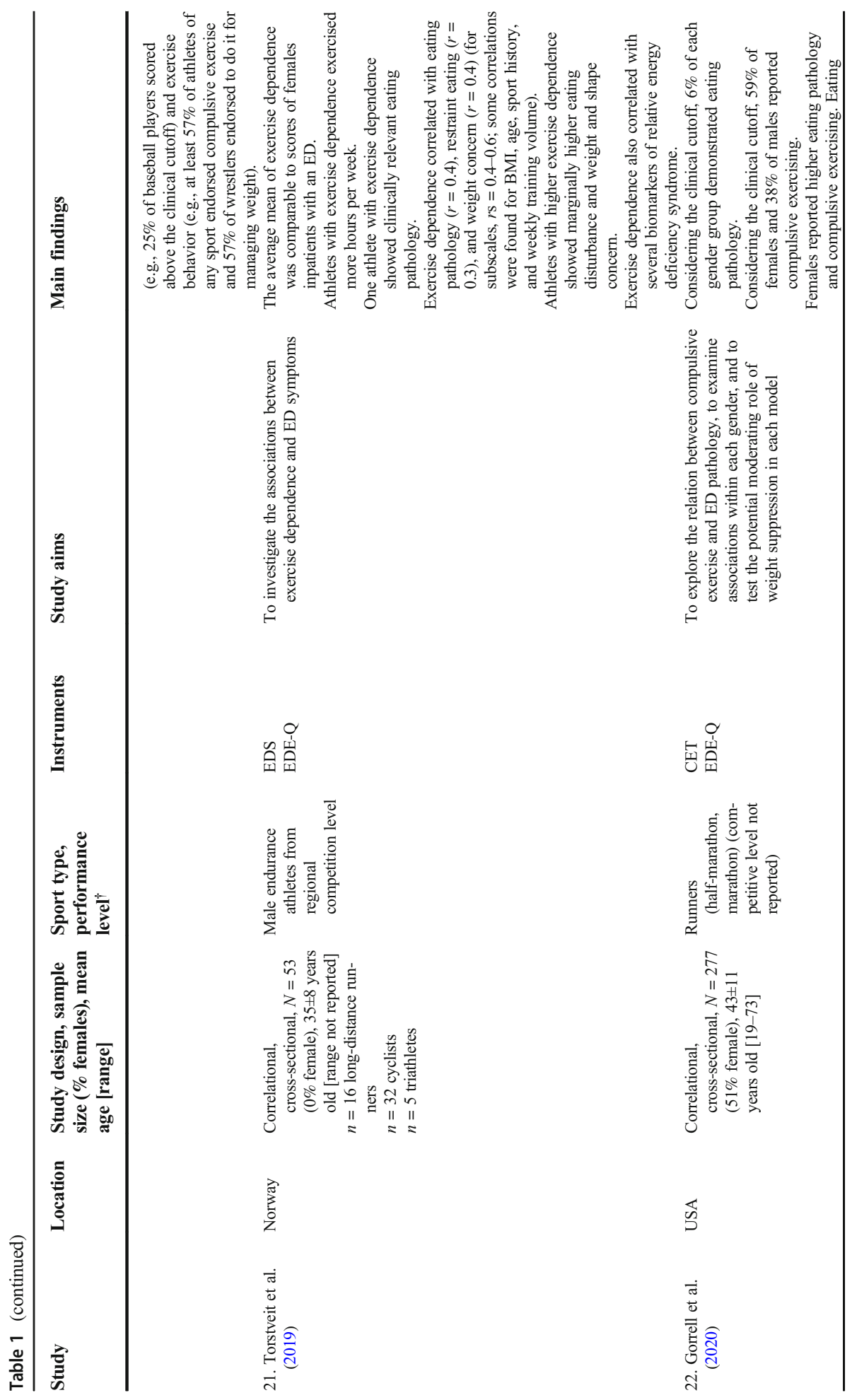

\section{Springer}




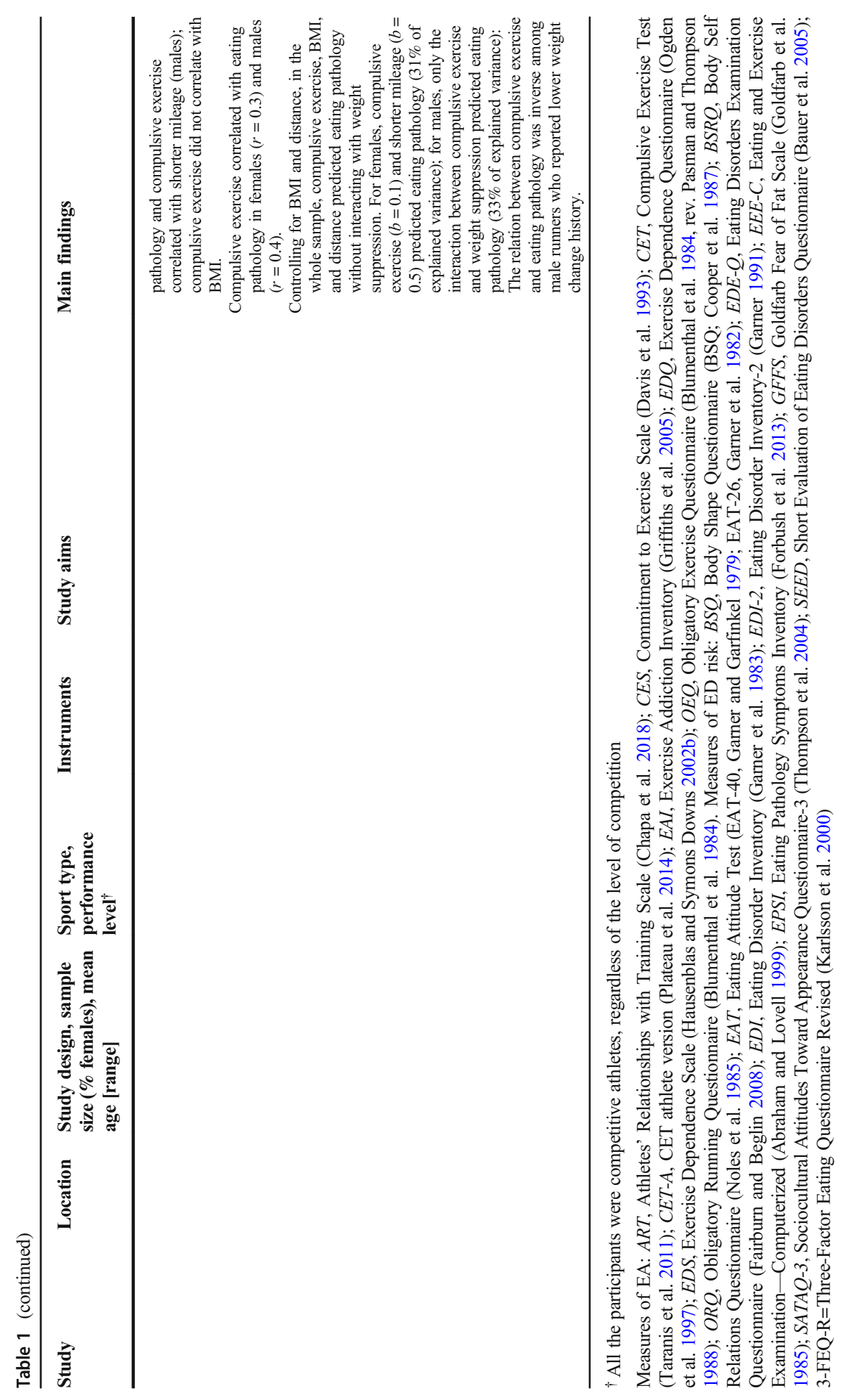




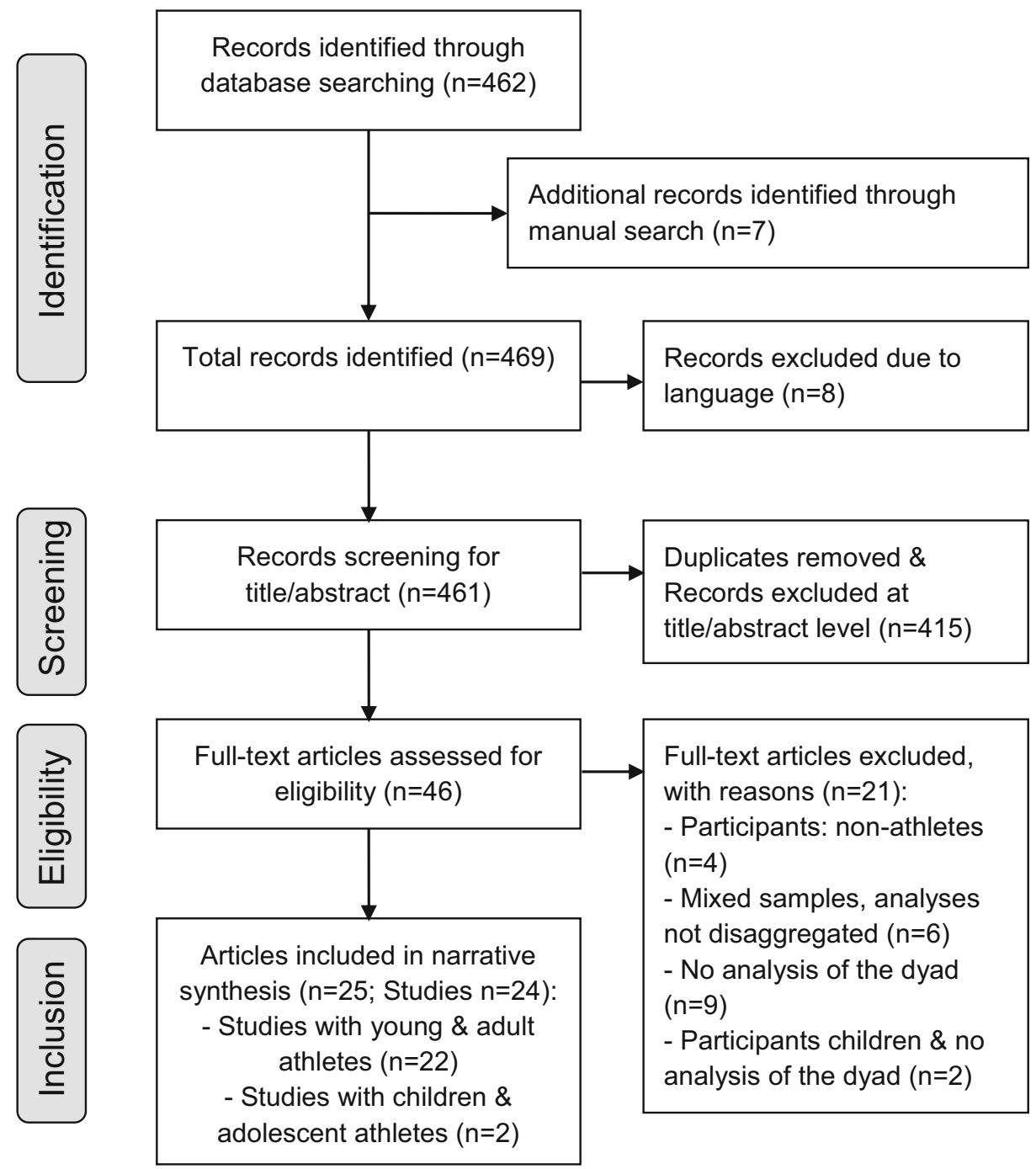

Fig. 1 Study selection and review process PRISMA flow diagram

Health \& Medical Collection, Medline, Nursing \& Allied Health Database, Latin America \& Iberia Database, Public Health Database, and Social Science Database), EBSCOhost (including SportDiscus and Psicodoc databases), and Cochrane Library. Search terms were defined through discussion among the research team based on pertinent literature. As there is no agreed-upon terminology, the terms commonly used in the literature were included in the search strategy for the present review.

The search terms used in equations incorporating AND and OR as logical operators were as follows: "exercise addiction," "exercise dependence," "abusive exercise," "compulsive exercise," "obligatory exercise," "excessive exercise," "exercise abuse," "overtraining," "eating disorder*," "disordered eating," "dysfunctional eating," "eating pathology," "athlet*," and "sport*" in the title, keywords, and/or abstract. A further specific search was conducted with 
Table 2 Exploring the role of correlates and possible mediators and moderators in the EA-EDs dyad

\section{Type of sport and features of athletic activity}

Research questions and main findings

Are athletes in endurance sports (e.g., running) $(1,4)$, ball sports (e.g., rugby) (16), any sport modality $(19,20)$, or lean and non-lean sports (13) at a higher risk for suffering from a combination of EA and EDs? Is the risk for EA higher as the intensity of sport increases (e.g., mileage in running) $(8,9,18,22)$; is this association independent of athletic success $(11)$ but moderated by sex $(18,22)$ ? Is the risk for the dyad independent of player field position and the associated demands on body size and weight (16)?

Conclusion

Any athlete, regardless of their discipline, is vulnerable; however, the risk for the dyad may be slightly higher in weight-sensitive sports.

Future lines of inquiry

More research is warranted discriminating among sport types in order to confirm that sport is a peripheral contributor or to explore an increased risk linked to sensitivity to weight or other features. The factors regarding body, weight, diet, and exercise may differ for men and women competing in different athletic modalities, even other lean sports (for instance, esthetic and weight-class sports); contrarily, it may be a similar nucleus for any athletic engagement, independent of the sport type. As others have concluded, there is no clear evidence that specific sports activities increase the risk for developing EA and/or EDs more than others (e.g., Díaz et al. 2018; Godoy-Izquierdo et al. 2019; Marques et al., 2018). Alternatively, individuals with or at risk for EDs may be turning to sports or forms of exercise that facilitate their illness (e.g., Cook and Luke 2017; Pritchard et al. 2007). Thus, more research is needed across different sports and athletic activity features, as different contexts could give rise to different patterns of EA-ED dyad manifestations.

\section{Performance level, history of the competition, and competition records}

Research questions and main findings

Does EA affect recreational, amateur, and non-professional athletes more than high-performance, professional, and elite athletes $(3,4)$, or, contrarily, is a higher competitive level associated with a higher risk for EA $(6,20)$ ? Is there no association at all $(12,13,19)$ ? Then, does competition level moderate the relationship between EA and EDs, affecting low-performance athletes more than high-performance athletes (6)? Are a longer history of competition and higher performance records risk factors for EA and linked with more severe EA (21), or, contrarily, there are no effects of sport or competition history $(2,3,11,12)$ ?

\section{Conclusion}

No conclusive evidence exists on competition-related issues.

Future lines of inquiry

More research is warranted to elucidate the influence of competition level, athletic history, and career success to gain further understanding of the influence of athletic factors.

\section{Training volume and season course}

Research questions and main findings

Do, as expected, athletes with EA show a greater amount of exercise training (e.g., weekly training hours, practicing other sports) $(2-4,21)$ or higher frequency of sessions $(11)$, or, contrarily, no associations between the volume of exercise and EA do exist $(7,11,14,19)$ ? When comparing primary and secondary EA, does exercise quantity rise as the grade of severity increases only in the case of primary EA (12)?

Conclusion

In contrast to other population-based groups, it seems that exercise quantity and a problematic commitment to exercise in athletes are not linked (or are linked at a lower rate).

Future lines of inquiry

Future research is needed addressing these and other sport-related factors, such as competition intensity and increased training volume to respond to the exigencies of competitions, which may be an important factor in both compulsive exercise and the association between compulsive exercise and eating disturbances. It would also be interesting to explore the dyad in conditions prone to exercise and body-related enhanced preoccupation (e.g., across periods of both in- and out-of-season time points or after injury), as a scarcity of studies covering these issues was found (e.g., for injury, 8,21 ).

\section{Gender/sex}

Research questions and main findings

Are females $(1,2,4,22)$ or men $(3,8)$ more vulnerable to EA, or are there no differences due to sex $(6,9,11,19)$ ? When weight-related issues (i.e., internalization of the athletic body ideal), are women more vulnerable to EA than men (9)?

Conclusion

Contradictory findings have been obtained for gender/sex.

Future lines of inquiry 
Table 2 (continued)

Much research has yet to be done to understand specific gender/sex issues. EDs have been extensively investigated among female athletes of all sports and competitive statuses, from amateur to elite, with consistent findings indicating their elevated vulnerability; there is also some growing research on EA. However, research with male samples of athletes is comparatively scarce and more recent, but as discrepant findings have been obtained (e.g., values of thinness vs. leanness and muscularity) indicating that males may have a unique risk for unhealthy exercise and eating behaviors, a more nuanced conceptualization of the male athlete EA-ED dyad is necessary. Furthermore, although the correlation between EA and EDs might be more apparent among women (Cunningham et al. 2016), male athletes may demonstrate a unique profile of ED pathology that includes the pivotal symptoms of unhealthy exercise (e.g., 20, 21).

Age

Research questions and main findings

Are younger $(4,9,11)$ or older $(21)$ athletes at a higher risk, or does age have no effects $(2,3,13,19)$ ? May other variables have a role in this relationship (e.g., athletic identity, 13)?

Conclusion

Mixed findings have been obtained for age.

Future lines of inquiry

Along with further research on age influences, a particular focus should also be placed on children and youth sports, since the evidence is increasingly showing an alarming prevalence of EA in this collective (e.g., Goodwin et al. 2016; Lichtenstein et al. 2018; Marques et al. 2019), with the dramatic fact that the development of unhealthy behaviors at younger ages leads to a higher risk for problem development, maintenance, and exacerbation at subsequent ages, comorbidity, health damage, athletic performance impairment, and career break. Increased drive or compulsion to exercise could transform the protective role of sport participation for youth into a harmful practice and a risk factor for EDs among the youngest. There is limited research on the dyad in the population of young athletes. One study (McCabe and Ricciardelli 2004) demonstrated that 12-to-17-year-old girls are more likely than boys to engage in disordered eating and be exercise dependent. It also supported the relationship between body concerns, body satisfaction, strategies to decrease weight or to increase muscle, use of supplements and steroids, and a focus on sport (contrary to the mere involvement in competitive sport) and disordered eating and EA, with some of these associations being different for boys and girls and dependent on pubertal timing. In another study conducted in 9-16-year-old girl swimmers (Hernández-Alcántara and GómezPeresmitré 2004), competitive anxiety and EA were correlated with a higher presence of risk factors for and manifestations of EDs. Younger athletes are more vulnerable to eating disturbances, as they are more susceptible to sociocultural and sport-specific pressures regarding body, weight, diet, and competition, less able to successfully cope with them, and less skilled in general for facing the high demands of competitive sport (e.g., Giel et al. 2016).

\section{Psychological factors}

Research questions and main findings

Are athletes experiencing EA and disordered eating different to athletes with only one of those conditions or to athletes with more healthy exercise and eating behaviors, e.g., in terms of a riskier motivational orientation (2-4), or a riskier combination of motives for exercising (e.g., weight or negative affectivity management instead of enjoyment or performance goals) and attitudes toward exercise (e.g., beliefs on exercise, exercise-(weightperformance connection) (7)?

Conclusion

There is a lack of research on the psychosocial features of athletes with EA and eating disturbances.

Future lines of inquiry

Research is warranted on different cognitive, emotional, motivational, behavioral, and social variables in athletes with EA and EDs, an area that is largely unstudied.

Some other variables could have a role in the EA-ED link, such as orthorexia, passion, and personality factors including perfectionism and the dark traits (e.g., González et al. 2018). Future research should also investigate the links of the EA-ED dyad with other behavioral addictions and unhealthy sport behaviors such as doping (e.g., Piacentino et al. 2017).

the terms "secondary exercise addiction," "secondary exercise dependence," and "secondary obligatory exercise." The same equations were used in Spanish. Retrieved titles and abstracts were independently assessed by the authors for eligibility for inclusion. Duplicate entries were removed. Relevant articles were then retrieved for full reading, and the references of those articles were searched to find any other relevant studies. All the authors reviewed full texts of 
potential studies, and decisions on inclusion were made by consensus. Data were extracted by two authors (DGI and IDC) and verified by two other authors (MRM and CLM), with discrepancies being resolved by agreement.

Primary source papers published in peer-reviewed journals up to April 2020 were eligible for inclusion if they were related to the disordered eating/EDs and EA dyad in athletes. Specific eligibility criteria included (1) empirical studies with a quantitative (either a crosssectional or longitudinal correlational design or an interventional design), qualitative or mixed methodology (study design criterion); (2) the study variables included disordered eating/EDs and EA, in any of their manifestations (outcome measure criterion); (3) the population of the study was (competitive) athletes, regardless of sport, age, or performance level (participants criterion); (4) regular empirical articles and meta-analyses published in peer-reviewed journals, excluding conference papers, proceeding abstracts, conceptual papers, reviews, books, and other types of gray literature, except when an empirical study was reported (source criterion); and (5) in English or Spanish (language criterion). Data extraction included author(s), date, country, study design, sample size, age, sex, sport type, performance level, study aims, instruments, and main findings pertaining to maladaptive eating and exercise behavior. Theoretical or review sources were considered for interpreting the findings.

This systematic review was performed and reported in accordance with the Preferred Reporting Items for Systematic Reviews and Meta-Analyses (PRISMA) guidelines (Moher et al. 2009; update Moher et al. 2015).

\section{Results}

\section{Literature Search Outcomes}

Figure 1 shows the flow through the systematic review process. The literature search yielded a total of 462 records, and seven additional articles were identified through a manual search. A total of 415 articles were rejected based on title and abstract information, and 8 studies were rejected due to language; none was inaccessible. After excluding duplicates, 46 of the potential papers were read and assessed for eligibility. Of them, 21 studies were finally rejected because (1) the sample was not composed of athletes at any level of competition, or when athletes were included, they represented a minor percentage and the data were not analyzed disaggregated by exercise group; or (2) the association between EA and eating pathology was not analyzed. Subsequently, a total of 25 potentially relevant articles were analyzed in depth. Two reports exclusively included children and adolescent athletes, and given this low number of studies focused on the youngest athletes, they were finally excluded (see Table 2). Finally, 23 papers were included. Two reports presented studies conducted with the same sample (the studies are listed as number 3 in Table 1) and therefore were considered as one study, allowing 22 studies for review.

\section{Study Characteristics}

The study characteristics are summarized in Table 1. All 22 studies were cross-sectional (although a few were derived from longitudinal-design parent studies, studies numbered 5 , 15, and 17 in Table 1), with four of them having a case-control/ex-post-facto design and the remaining 18 being descriptive, correlational studies. No qualitative report was found 
exclusively, including athletes. The samples were composed of young and adult athletes with a broad age range. Mostly, both sexes were included; however, three studies were limited to females, and three studies were limited to males. In addition, there were five articles presenting outcomes for more than one population; specifically, three studies included non-athletes, and two studies included a clinical subsample of athletes with EDs. Studies including different populations disaggregated findings by population and thus were included following the inclusion criteria.

Sports were varied. A total of 55\% of studies were focused on endurance sports (running: 8 studies; triathlon: 2 studies; ironman: 1 study; cycling: 1 study), whereas $41 \%$ included several sport modalities and one study included rugby players. The performance level was reported in $64 \%$ of the studies and not reported in $32 \%$ of them. One study did not include detailed information on the type of sport or the level of performance of the athletes.

To measure the risk for and manifestations of EA, the Exercise Dependence Scale (EDS), the Obligatory Exercise Questionnaire (OEQ; original version ORQ), and the Compulsive Exercise Test (CET) or its adaptation for athletes were each used in five studies, the Exercise Dependence Questionnaire (EDQ) was used in four studies, the Exercise Addiction Inventory (EAI) was used in one study, and the Commitment to Exercise Scale (CES) was used in another study. One study created a specific questionnaire to assess EA, and another study used another tool specifically designed for athletes (ART). The studies were mainly conducted in the USA (12 studies) and Europe (6 studies), and the remaining ones in other regions (6 studies).

\section{Main Findings: Prevalence and Direction of the Association Between EA and EDs}

The findings and characteristics of the 22 studies featured in this review are presented in Table 1. In 12 studies, one outcome variable was the prevalence of risk for EA. Overall prevalence estimates varied between 1 and 59\% for primary EA and between 1 and $80 \%$ for secondary EA; however, several populations based on sport type and sample characteristics were studied. Based on the present review (see Table 1), for primary EA, the figures are 1-51\% for runners (studies 2, 7, and 8), 30\% for triathletes (study 3), 8-9\% for ironman competitors and cyclists (studies 11 and 12), and 15-30\% for athletes in a non-disaggregated variety of sports (studies 4, 13, and 19). Only two studies disaggregated prevalence rates by sex: In both running (study 22) and a variety of sports (study 19), women were between 55 and $67 \%$ more likely to report EA than men. Moreover, one study (13) specifically distinguished between lean (40\%) and non-lean (26\%) sports for calculating the prevalence of EA among female athletes.

For secondary EA, the rates are 20-80\% for runners (studies 7 and 8), 22\% for triathletes (study 3 ), $1 \%$ for cyclists (study 12), and $13-57 \%$ for athletes in a non-disaggregated variety of sports (studies 4 and 20). None of the studies disaggregated prevalence rates by sex or weightsensitive nature of sports. Comparatively, two studies ( 7 and 8) showed a nearly 30 percent points higher prevalence of EA co-occurring with eating pathology compared to pure EA, whereas one study (4) found similar rates for both conditions and only one (study 3 ) found a difference of $8 \%$ favoring the prevalence of pure EA over the EA-EDs dyad. All these findings suggest that both the pure and dyadic forms of EA exist among athletes, but the EA-ED dyad is more prevalent.

Irrespective of the prevalence rates, a constant could be seen: The means and range of scores indicate that for many athletes excessive exercise is a habitual form of relationship with training. As Pritchard et al. (2007) noted, athletes' responses indicate that some of them 
excessively exercise somewhere between "sometimes" and "often," while others exceed this by "very often" overexercising.

Regarding the direction of the associations between exercise and eating pathology, in 10 of the 22 studies, the main outcome variable was the risk for or manifestations of eating pathology, with unhealthy exercise engagement as an antecedent (studies 1, 2, 6, 7, 10, 11, $15,18,21$, and 22). In contrast, six studies $(8,9,14,16,17$, and 19) explored EA as an effect or outcome of eating pathology, namely the secondary form of EA. Three studies $(3,4$, and 12$)$ treated both EA and eating pathology or risk factors as the predictors or antecedent variables of a third variable. One study (20) explored the influence of third variables on both EA and eating disturbance. The remaining two studies explored a three-link chain, i.e., eating risk factors-EAeating pathology (study 5) or interchanged the direction of the connection in each analysis (study 13).

\section{Discussion}

The present review summarizes the findings of studies addressing the association of dysfunctional eating and EA in the sport context. Twenty-two cross-sectional studies were systematically reviewed, all supporting the reality of the dyad of EA and eating pathology among a number of athletes. The main findings of the reviewed studies will be discussed in detail. In order to distinguish between the reviewed studies and other evidence, the reviewed studies will continue to be cited with the numbers assigned in Table 1.

Before continuing, some clarifications need to be made. This review was limited to EA. Nevertheless, athletes report frequently adopting extreme weight-control practices, including overexercising, for instance prior to competition, during resting periods, or after injury. The literature on the eating dysfunction continuum in sports is also full of studies investigating such practices when body image or eating pathology exists. However, overexercising does not mean EA or an associated ED (e.g., overexercising for weight control), nor these possibilities can be excluded without assessing in more detail the addictive, compulsory, and motivational components of such practices. Thus, our findings must be put in the context of extensive research on body image, weight control, and EDs in sports for a broader picture of the role of exercise in relation to eating attitudes and behaviors among athletes.

Moreover, this review focused on the intertwined combination of eating and exercise behavior, also known as secondary EA in classical terms. Primary EA without any reference to another disturbance was excluded (e.g., Trott et al. 2020a). However, it is possible that one of the reasons for compulsive exercise among those with primary EA is ultimately related to the control of weight, body composition and appearance, concerns of gaining weight, and body-related distress (Cook et al. 2014; Lichtenstein et al. 2017). As Magee et al. (2016) concluded in their study, athletes with apparently primary EA showed dysfunctional eating characteristics and thus probably had exercise dependence symptoms that were secondary to an ED (11). By excluding the research on manifestations of primary EA from this synthetic review, conclusions regarding this possibility cannot be drawn.

\section{Findings on the Association Between EA and the Disordered Eating/EDs Continuum}

Overall, evidence from the reviewed studies suggests that the association between EA and eating pathology is homogeneous among and within diverse athletic samples: Unhealthy, 
abusive exercise is consistently related to eating pathology. However, some discrepancies were observed among the findings, which could be explained by the instruments used to assess both phenomena or by the fact that the athlete groups comprised amateur to elite athletes from different sports as well as age- and sex-related factors (e.g., Marques et al., 2018; Szabo et al. 2015). The intervention of third variables might also underlie this association (see Table 2). It is worth noting that two studies (18 and 22) indicate that EA pathology might be protective for EDs, yet some additional variables might explain this anomalous finding. All these inconsistencies need to be addressed in future research.

Specifically, it has been found that EA and disordered eating are significantly correlated ( $r \mathrm{~s}$ $=0.14-0.69)(2,5,7,14,15,17,18,21,22)$, even higher $(10)$, and are correlated similarly in women $(r \mathrm{~s}=0.27-0.40)$ and men $(r \mathrm{~s}=0.28-0.42)$. Some findings also seem to point out that athletes would be slightly "protected" in this association compared to other populations since the strength of the association has been found to be lower among athletes than non-athletes in one study (17). The co-occurrence of and correlations between addictive or compulsive exercise and disordered eating raise many questions on whether unhealthy exercise is a contributor to or an outcome of underlying maladaptive eating behavior. In other words, in distinguishing excessive or compulsory exercise that occurs with EDs, it is essential to know whether athletes with a higher risk for or symptoms of eating disturbance exercise excessively to avoid gaining weight, to control the appearance, or to manage body-related mood annoyance - secondary EA - or whether, alternatively, excessive exercise contributes to disordered eating. The present review demonstrates that both directions have been explored and supported, yet there are almost two times more studies exploring the influences of EA on eating pathology than the opposite pathway.

Several studies have found that EA dimensions predict ED risk $(6,7,10,22)$, with estimates ranging between 0.20 and 0.54 , with the intervention of mediating or moderating variables such as competitive level (e.g., 6) or weight history (e.g., 22) or without the intervention of third variables such as athletic identity (e.g., 7). In addition, it has been found that athletes showing EA also score higher on a diversity of measures used to screen for ED risk than athletes with no unhealthy exercise habits $(7,11,13,21)$ and similar to athletes suffering from an ED (13). Note that research has thus mainly explored the alternative pathway to secondary addiction to exercise. This research demonstrates that although a relationship between exercise behavior and eating pathology is evident, there is a large amount of ED risk that is not explained by maladaptive exercise behavior, and future research on EDs in sports is warranted for a more comprehensive understanding of pathological eating in athletes.

Alternatively, namely in support of the secondary EA, it has been found that several risk factors for EDs, such as weight and shape preoccupation, internalization of the thin and the athletic body ideals, body dissatisfaction, and abnormal eating attitudes as well as disordered eating behavior, also predict EA, with estimates ranging from 0.20 to $0.33(5,19)$. Some findings point to possible intervening variables, such as physical appearance comparisons (e.g., 16). It has been affirmed that, to date, it is unknown whether EA risk differs substantially in individuals with and without EDs (Trott et al. 2020b). This review supports it does differ, at least among athletes. When athletes with primary and secondary exercise dependence have been compared, those with secondary EA have shown higher scores in excessive exercise measures (e.g., 3, 4, 8), yet others have found no differences (12). Moreover, Plateau et al. (2017) concluded that athletes with EA are more than 3 times more likely to have an ED (13). Similarly, athletes with a higher risk for EDs also show higher levels of EA (16). In addition, up to $80 \%$ of athletes with disordered eating also show features of EA (7). However, only a 
few studies have included clinical samples of athletes with an established ED (13-16), demonstrating that athletes with EA show similar compulsive exercise than athletes with ED risk (14), and that athletes with current or previous EDs have higher EA and eating pathology than athletes without eating pathology $(13,15)$ and similar to non-athletes with ED (16) and clinical samples of female inpatients (21). Some studies expressly excluded athletes with EDs, impeding a further understanding of the role of eating pathology. Future research is warranted including several types of EDs and comparing EA features across them; the study of the dyad as a function of the type of ED is needed, given that different prevalences and correlates have been observed for each disorder (Cunningham et al. 2016; Dalle Grave 2009; Trott et al. 2020b). Distinguishing between EDs may also help in determining to what extent the risk for a particular ED is increased through an association with abusive exercise (Adams 2009).

\section{Methodological Limitations of the Research on the EA and Disordered Eating Dyad}

Notably, since all the studies were conducted with a correlational, cross-sectional design, no cause-effect conclusions can be obtained. Longitudinal and experimental studies would be helpful in understanding the EA-ED dyad by establishing the direction of the association between problematic exercise and eating pathology in athletes. In addition, the small-tomoderate relationships and prediction estimations, as well as the low-to-moderate values of the effect size coefficients obtained in comparisons, indicate the value of adopting theoretical perspectives to allow the examination of the exercise and dietary behavior dyad within a broader athlete psychosocial context to explain higher amounts of variance. Most researchers have studied these relationships in isolation, a few included potential mediators and moderators, and only two were focused on testing a conceptual model relating relevant factors for EA and disordered eating; thus, there is a need for additional research addressing these issues in the association between maladaptive eating and exercise behaviors. Table 2 presents a summary of the potential contributions of some third variables intervening as mediators and moderators that future research must investigate for a deeper understanding of disordered exercise and eating behaviors in athletes.

Research on psychological factors contributing to or correlating with EA and the dyad is scarce and is also warranted (see also Table 2). Among others, athletic identity and body image and weight concern issues should be investigated in depth. Further exploration of the role of athletic identity in the causation or manifestations of EA and EDs, for which contradictory findings exist, is encouraged. Whereas self-identification with the athletic role and overcommitment have been related to increased risk for EA and EDs $(7,9)$, athletic identity has not been found to mediate the relation between exercise overtraining and unhealthy eating behaviors (7). Other studies have found that athletic identity correlates with EA only in females with weight control exercise and when body mass index (BMI) is a covariate (Turton et al. 2017). Athletic identity has also been related to an increased risk for EA, not being directly related to ED pathology but moderated by unhealthy exercise, at least in shorter distance runners (18). In other words, among those with less mileage, i.e., half-marathon compared to marathon runners, high athletic identity and compulsive exercise may be protective against ED risk; among these individuals, the risk for ED may be significantly elevated among those who report lower exercise identity (18). Another surprising "protective" effect is seen among runners when weight suppression (changes in weight) is considered (22). It was found that in male runners, the interaction of weight suppression and compulsive exercise predicted eating pathology: At high levels of weight suppression, males with higher 
compulsive exercise reported elevated ED pathology, but at lower levels of weight variation, men with lower compulsive exercise endorsed greater eating pathology. Since these are the unique anomalous findings in the trends of the association between pathological exercise and eating behaviors that were found, the "protective" power of EA for EDs, e.g., when athletic identity or lifelong weight history is considered, should be better explored in the future.

In addition, research is also needed to thoroughly address the role of body perceptions and body satisfaction at the heart of both EA and the EA-EDs dyad. Body image seems to play a key role in the relationship between exercise and eating disturbances. As found in this review, athletes with greater EA, like those with EDs, show overestimation of their body weight and size, higher weight preoccupation, shape concerns, drive for thinness, internalization of body ideals, and greater body dissatisfaction. In a study (6), body dissatisfaction and excessive exercise predicted ED pathology, and it was concluded that efforts to attain the ideal body to increase body satisfaction ultimately lead to unhealthy behaviors. Moreover, one study indicated that, whereas EA could not predict ED pathology, body perceptions were found to be a necessary mediator to establish the association between eating disturbances and EA (19). In addition, athletes with greater EA also show lower BMI/weight than their non-addicted counterparts $(2-4,9,21)$, although it is unknown whether this is a result of training volume or - eventually pathologic - weight management. Whereas others have not found a significant link between BMI and EA $(13,18)$, indicating that objective weight might not be a contributing factor among athletes, perceptions of weight change or history of weight change might be a relevant variable for EA and ED (e.g., 22).

In summary, there is a need for exploring the role of potential psychological correlates of the EA-EDs dyad. Identifying the intervening third variables provides points for risk screening and early identification of EDs and EA as well as clinical targets at which preventive or therapeutic interventions may be directed.

Finally, the phenomenological, experiential aspects of EA and EDs as well as of their interaction merit further research. Narrative approaches allow us to better understand athletes with disordered eating (de Bruin 2017), and the same could be expected for EA experiences (Juwono and Szabo 2020). No report was found for this review on the subjective experiences, needs, and concerns of athletes experiencing eating disturbances and exercise compulsion as a compensatory mechanism, on factors contributing to or maintaining problematic eating and exercise behavior in athletes or on strategies for overcoming an ED-exercise problem, whatever the relationship may be. Some existing papers combined (female) athletes, exercisers, and patients with EDs (e.g., Bamber et al. 2000; Johnston et al. 2011; Kolnes and Rodriguez-Morales 2016; Warner and Griffiths 2006) and illustrate that, contrary to ED patients and non-competitive exercisers, among athletes it is particularly difficult to distinguish problematic exercise from functional, healthy exercise for sports performance, and that the pathological status of exercise and eating practices is less straightforward; all this is derived from the fact that weight is a key factor in sports performance (Bamber et al. 2000).

These reports on self-lived experiences with eating and exercise disturbances also highlight the features of problematic exercise, its narrow association with eating pathology, weight control and appearance management, the internalization and constant pursuit of the athletic body ideal, and the existence of external pressures (e.g., from coaches) to conform to the weight and appearance expectations put on sportsmen and sportswomen. These discourses demonstrate that problematic exercise is manifested mostly in the context of EDs and higher psychological distress (Bamber et al. 2000). Another recurrent motivation for and function of problematic exercise is mood regulation of embodied emotional states and self-identity 
establishment (Kolnes and Rodriguez-Morales 2016). Importantly, these narratives also demonstrate that individuals with excessive exercise also perceive benefits from their problematic behavior (e.g., improved sense of achievement, enhanced performance, higher mental control), thus complicating problem awareness and management.

EDs are so common in sports that they are among the most studied mental health issues in athletes, and research and clinical practice have allowed us to be aware of the unique experiences facing athletes with these disorders (Reardon and Factor 2010). Consequently, qualitative research with interviews and focus groups may also allow for an in-depth investigation of the factors contributing to EA-ED development, maintenance, or recovery as well as of the intimate, profound lived experiences when experiencing these conditions.

\section{Conclusions}

This is the first review to systematically examine the association of dysfunctional eating and EA issues in the sport context. Despite the increasing amount of research examining disordered eating and problematic exercise, as well as the potential links between them, the dyad remains an understudied subject. Limited evidence is available that specifically addresses dysfunctional eating and exercise abuse in athletes, and additional research is needed to gain an understanding of the complexities involved in exercise dependence and disordered eating, increase awareness of the problem in the athletic population, i.e., athletes, coaches, health-care professionals, and so forth, and validate optimal strategies for the detection, management, and prevention of these related conditions in the sport context.

This overview, by synthesizing and critically discussing the research on the dyad of EA and EDs in sports, presents advancements and gaps regarding the links between exercise and eating disturbances as common comorbidities in the athletic context. Supporting the classical distinction between primary and secondary EA, eating pathology has been demonstrated to be a risk factor for unhealthy engagement in exercise by athletes. In addition, compulsive exercise and EA have an important role in the development and maintenance of disordered eating, particularly in the extent to which exercise is undertaken primarily to change body weight and appearance.

As future lines of inquiry, continued research is needed to better understand how participation in competitive sports influences the presentation, treatment, and outcomes of EDs and EA. Exploring intraindividual combinations of maladaptive eating and exercise behaviors would help to identify distinguishable profiles, each associated with different correlates and outcomes. While further longitudinal and experimental research is needed to establish etiological associations, qualitative research is also warranted for an in-depth understanding of the complete picture. Recommended priorities are the development of consensual operationalization of the construct and conceptual comprehensive models, validated assessment tools to improve the identification of EDs and EA issues specifically in athletes and effective interventions for both the management and the prevention of such conditions. The detrimental consequences on athletes' health and athletic performance of EA in conjunction with disordered eating require further research.

As derived practical applications, identifying and understanding the exact mechanisms underlying EA and explaining the varied subjective experiences with it and the wide array of EA comorbidities (e.g., disordered eating) and outcomes on health and performance could have important practical implications. All this knowledge will lead to earlier identification of athletes with problematic behaviors and to the development of treatment strategies that are 
tailored toward each athlete's maladaptive exercise and eating behavior profile, with the aim of preventing further deterioration, achieving the greatest well-being and allowing a safe return to competition.

This condition warrants further investigation, and this review intends to show researchers what is known and what is necessary to address in the future. This condition also requires awareness and consideration by athletes, coaches, sports physicians, and sports psychologists, and this review intends to serve as an introductory source of education for them.

Author Contribution All authors contributed to the study conception and design, literature search, and data analysis. The first draft of the manuscript was written by DGI and CLM and reviewed by the remaining authors. All authors read and approved the final manuscript. DGI supervised the research process.

Funding Open Access funding provided thanks to the CRUE-CSIC agreement with Springer Nature. This study was funded by the financial aid conceded to the Research Group CTS267 by Junta de Andalucía (Spain). Funding for open access charge: Universidad de Granada/CBUA.

\section{Declarations}

Conflict of Interest The authors declare no competing interests.

Open Access This article is licensed under a Creative Commons Attribution 4.0 International License, which permits use, sharing, adaptation, distribution and reproduction in any medium or format, as long as you give appropriate credit to the original author(s) and the source, provide a link to the Creative Commons licence, and indicate if changes were made. The images or other third party material in this article are included in the article's Creative Commons licence, unless indicated otherwise in a credit line to the material. If material is not included in the article's Creative Commons licence and your intended use is not permitted by statutory regulation or exceeds the permitted use, you will need to obtain permission directly from the copyright holder. To view a copy of this licence, visit http://creativecommons.org/licenses/by/4.0/.

\section{References}

Abraham, S., \& Lovell, N. (1999). Eating and exercise examination-Computerised EEEC. Ashwood Medical. Adams, J. (2009). Understanding exercise dependence. Journal of Contemporary Psychotherapy, 39(4), 231240. https://doi.org/10.1007/s10879-009-9117-5

Adams, J., \& Kirkby, R. J. (1998). Exercise dependence: A review of its manifestation, theory and measurement. Research in Sports Medicine: An International Journal, 8(3), 265-276. https://doi.org/10.1080/ 15438629809512532

Allegre, B., Souville, M., Therme, P., \& Griffiths, M. (2006). Definitions and measures of exercise dependence. Addiction Research \& Theory, 14(6), 631-646. https://doi.org/10.1080/16066350600903302

Bamber, D., Cockerill, I. M., Rodgers, S., \& Carroll, D. (2000). "It's exercise or nothing": A qualitative analysis of exercise dependence. British Journal of Sports Medicine, 34(6), 423-430. https://doi.org/10.1136/bjsm.34.6.423

Bär, K. J., \& Markser, V. Z. (2013). Sport specificity of mental disorders: The issue of sport psychiatry. European Archives of Psychiatry and Clinical Neuroscience, 263(S2), 205-210. https://doi.org/10.1007/ s00406-013-0458-4

Bauer, S., Winn, S., Schmidt, U., \& Kordy, H. (2005). Construction, scoring and validation of the Short Evaluation of Eating Disorders (SEED). European Eating Disorders Review, 13(3), 191-200. https://doi. org/10.1002/erv.637

Berczik, K., Szabó, A., Griffiths, M. D., Kurimay, T., Kun, B., Urbán, R., \& Demetrovics, Z. (2012). Exercise addiction: Symptoms, diagnosis, epidemiology, and etiology. Substance Use \& Misuse, 47(4), 403-417.

Blaydon, M. J., \& Lindner, K. J. (2002). Eating disorders and exercise dependence in triathletes. Eating Disorders, 10(1), 49-60. 
Blaydon, M. J., Lindner, K. J., \& Kerr, J. H. (2002). Metamotivational characteristics of eating-disordered and exercise-dependent triathletes: An application of reversal theory. Psychology of Sport and Exercise, 3(3), 223-236.

Blaydon, M. J., Linder, K. J., \& Kerr, J. H. (2004). Metamotivational characteristics of exercise dependence and eating disorders in highly active amateur sport participants. Personality and Individual Differences, 36(6), 1419-1432. https://doi.org/10.1016/S0191-8869(03)00238-1

Blumenthal, J. A., O’Toole, L. C., \& Chang, J. L. (1984). Is running an analogue of anorexia nervosa? Journal of the American Medical Association, 252, 520-523.

Chapa, D. A., Hagan, K. E., Forbush, K. T., Perko, V. L., Sorokina, D. A., Alasmar, A. Y., et al. (2018). The Athletes' Relationships with Training scale (ART): A self-report measure of unhealthy training behaviors associated with eating disorders. International Journal of Eating Disorders, 51(9), 1080-1089. https://doi. org/10.1002/eat.22960

Compte, E. J., Murray, S. B., Sepúlveda, A. R., Schweiger, S., Bressan, M., \& Torrente, F. (2018). What position do you play? Eating disorder pathology among rugby players, and the understudied role of player position. International Journal of Eating Disorders, 51(8), 1015-1019. https://doi.org/10.1002/eat.22933

Cook, B. J., \& Hausenblas, H. A. (2008). The role of exercise dependence for the relationship between exercise behavior and eating pathology: Mediator or moderator? Journal of Health Psychology, 13(4), 495-502. https://doi.org/10.1177/1359105308088520

Cook, B., \& Luke, R. (2017). Primary and secondary exercise dependence in a sample of cyclists. International Journal of Mental Health and Addiction, 15(2), 444-451. https://doi.org/10.1007/s11469-017-9745-z

Cook, B., Karr, T. M., Zunker, C., Mitchell, J. E., Thompson, R., Sherman, R., Crosby, R. D., Cao, L., Erickson, A., \& Wonderlich, S. A. (2013). Primary and secondary exercise dependence in a community-based sample of road race runners. Journal of Sport and Exercise Psychology, 35(5), 464 469.

Cook, B., Hausenblas, H., \& Freimuth, M. (2014). Exercise addiction and compulsive exercising: Relationship to eating disorders, substance use disorders and addictions. In T. D. B. Brewerton (Ed.), Eating disorders, addictions and substance use disorders research, clinical and treatment perspectives (pp. 127-144). Springer.

Cooper, P. J., Taylor, M. J., Cooper, Z., \& Fairbum, C. G. (1987). The development and validation of the Body Shape Questionnaire. International Journal of Eating Disorders, 6(4), 485-494.

Cunningham, H. E., Pearman, S., \& Brewerton, T. D. (2016). Conceptualizing primary and secondary pathological exercise using available measures of excessive exercise. International Journal of Eating Disorders, 49(8), 778-792. https://doi.org/10.1002/eat.22551

Dalle Grave, R. (2009). Features and management of compulsive exercising in eating disorders. The Physician and Sportsmedicine, 37(3), 20-28. https://doi.org/10.3810/psm.2009.10.1725

Dalle Grave, R., Calugi, S., \& Marchesini, G. (2008). Compulsive exercise to control shape or weight in eating disorders: Prevalence, associated features and treatment outcome. Comprehensive Psychiatry, 49(4), 346352. https://doi.org/10.1016/j.comppsych.2007.12.007

Danielsen, M., Rø, Ø., Romild, U., \& Bjørnelv, S. (2016). Impact of female adult eating disorder inpatients' attitudes to compulsive exercise on outcome at discharge and follow-up. Journal of Eating Disorders, 4, 7. https://doi.org/10.1186/s40337-016-0096-0

Davis, C. (2000). Exercise abuse. International Journal of Sport Psychology, 31(2), 278-289.

Davis, C., Brewer, H., \& Ratusny, D. (1993). Behavioral frequency and psychological commitment: Necessary concepts in the study of excessive exercising. Journal of Behavioral Medicine, 16, 611-628.

de Bruin, A. K. (2017). Athletes with eating disorder symptomatology, a specific population with specific needs. Current Opinion in Psychology, 16, 148-153. https://doi.org/10.1016/j.copsyc.2017.05.009

De Coverley Veale, D. M. (1987). Exercise dependence. British Journal of Addiction, 82(7), 735-740. https:// doi.org/10.1111/j.1360-0443.1987.tb01539.x

Di Lodovico, L., Poulnais, S., \& Gorwood, P. (2019). Which sports are more at risk of physical exercise addiction: A systematic review. Addictive Behaviors, 93, 257-262. https://doi.org/10.1016/j.addbeh.2018. 12.030

Díaz, I., Godoy-Izquierdo, D., Navarrón, E., Ramírez, M. J., \& Dosil, J. (2018). Eating disorders in sports and football: An updated review. Cuadernos de Psicología del Deporte, 18(2), 45-56.

Elbourne, K. E., \& Chen, J. (2007). The continuum model of obligatory exercise: A preliminary investigation. Journal of Psychosomatic Research, 62(1), 73-80. https://doi.org/10.1016/j.jpsychores.2004.12.003

Fairburn, C. G., \& Beglin, S. (2008). Eating Disorder Examination Questionnaire (EDE-Q 6.0). In C. G. Fairburn (Ed.), Cognitive behavior therapy and eating disorders (pp. 309-313). Guilford.

Fewell, L. K., Nickols, R., Tierney, A. S., \& Levinson, C. A. (2018). Eating disorders in sport: Comparing eating disorder symptomatology in athletes and non-athletes during intensive eating disorder treatment. Journal of Clinical Sport Psychology, 12(4), 578-594. https://doi.org/10.1123/jcsp.2018-0046 
Forbush, K. T., Wildes, J. E., Pollack, L. O., Dunbar, D., Luo, J., Patterson, K., Petruzzi, L., Pollpeter, M., Miller, H., Stone, A., Bright, A., \& Watson, D. (2013). Development and validation of the Eating Pathology Symptoms Inventory (EPSI). Psychological Assessment, 25(3), 859-878. https://doi.org/10.1037/a0032639

Freimuth, M., Moniz, S., \& Kim, S. R. (2011). Clarifying exercise addiction: Differential diagnosis, co-occurring disorders, and phases of addiction. International Journal of Environmental Research and Public Health, 8(10), 4069-4081. https://doi.org/10.3390/ijerph8104069

Gapin, J. I., \& Petruzzello, S. J. (2011). Athletic identity and disordered eating in obligatory and non-obligatory runners. Journal of Sports Sciences, 29(10), 1001-1010. https://doi.org/10.1080/02640414.2011.571275

Garner, D. M. (1991). The eating disorder inventory-2 professional manual. Psychological Assessment Resources.

Garner, D. M., \& Garfinkel, P. E. (1979). The Eating Attitudes test: An index of the symptoms of anorexia nervosa. Psychological Medicine, 9, 273-279. https://doi.org/10.1017/S0033291700030762

Garner, D. M., Olmsted, M. P., Bohr, Y., \& Garfinkel, P. E. (1982). The Eating Attitudes Test: Psychometric features and clinical correlates. Psychological Medicine, 12, 871-878. https://doi.org/10.1017/ S0033291700049163

Garner, D. M., Olmstead, M. P., \& Polivy, J. (1983). Development and validation of a multidimensional eating disorder inventory for anorexia nervosa and bulimia. International Journal of Eating Disorders, 2, 15-34.

Giel, K. E., Hermann-Werner, A., Mayer, J., Diehl, K., Schneider, S., Thiel, A., et al. (2016). Eating disorder pathology in elite adolescent athletes. International Journal of Eating Disorders, 49(6), 553-562. https://doi. org/10.1002/eat.22511

Godoy-Izquierdo, D., Díaz, I., Ramírez, M. J., Navarrón, E., \& Dosil, J. (2019). Risk for eating disorders in "high"-and "low"-risk sports and football (soccer): A profile analysis with clustering techniques. Revista de Psicología del Deporte, 28(2), 117-126.

Goldfarb, L. A., Dykens, E. A., \& Gerrard, M. (1985). The Goldfarb Fear of Fat Scale. Journal of Personality Assessment, 49(3), 329-332. https://doi.org/10.1207/s15327752jpa4903_21

Gonçalves, J., Costa, P. N., Faria, M., do Espírito-Santo, G., Assis, M., \& Palma, A. (2019). Exercise dependence: An updated systematic review. Journal of Exercise Physiology Online, 22(5), 105-125.

González, J., Garita-Campos, D., \& Godoy-Izquierdo, D. (2018). The Dark Triad of Personality and its psychological implications in sport. A systematic review. Cuadernos de Psicología del Deporte, 18(2), 187-204.

Goodwin, H., Haycraft, E., \& Meyer, C. (2016). Disordered eating, compulsive exercise, and sport participation in a UK adolescent sample. European Eating Disorders Review, 24(4), 304-309. https://doi.org/10.1002/ erv. 2441

Gorrell, S., \& Anderson, D. A. (2018). Athlete identity and eating pathology in distance runners: When compulsive exercise matters. Journal of Clinical Sport Psychology, 12(4), 647-657. https://doi.org/10. 1123/jcsp.2018-0016

Gorrell, S., Nagata, J. M., Hill, K. B., Carlson, J. L., Shain, A. F., Wilson, J., Alix Timko, C., Hardy, K. K., Lock, J., \& Peebles, R. (2019). Eating behavior and reasons for exercise among competitive collegiate male athletes. Eating and Weight Disorders-Studies on Anorexia, Bulimia and Obesity., 26, 75-83. https://doi.org/ 10.1007/s40519-019-00819-0

Gorrell, S., Scharmer, C., Kinasz, K., \& Anderson, D. (2020). Compulsive exercise and weight suppression: Associations with eating pathology in distance runners. Eating Behaviors, 36, 101358. https://doi.org/10. 1016/j.eatbeh.2019.101358

Griffiths, M. D., Szabo, A., \& Terry, A. (2005). The Exercise Addiction Inventory: A quick and easy screening tool for health practitioners. British Journal of Sports Medicine, 39(6), e30. https://doi.org/10.1136/bjsm. 2004.017020

Gümmer, R., Giel, K. E., Schag, K., Resmark, G., Junne, F. P., Becker, S., Zipfel, S., \& Teufel, M. (2015). High levels of physical activity in anorexia nervosa: A systematic review. European Eating Disorders Review, 23(5), 333-344. https://doi.org/10.1002/erv.2377

Hausenblas, H. A., \& Symons Downs, D. (2002a). Exercise dependence: A systematic review. Psychology of Sport and Exercise, 3(2), 89-123.

Hausenblas, H. A., \& Symons Downs, D. (2002b). How much is too much? The development and validation of the exercise dependence scale. Psychology and Health, 17(4), 387-404.

Hernández-Alcántara, A., \& Gómez-Peresmitré, G. (2004). Factores de riesgo asociados con conducta alimentaria en mujeres nadadoras. Revista Mexicana de Psicología, 21(1), 29-36.

Johnston, O., Reilly, J., \& Kremer, J. (2011). Excessive exercise: From quantitative categorisation to a qualitative continuum approach. European Eating Disorders Review, 19(3), 237-248. https://doi.org/10.1002/erv.970

Juwono, I. D., \& Szabo, A. (2020). 100 cases of exercise addiction: More evidence for a widely researched but rarely identified dysfunction. International Journal of Mental Health and Addiction, 1-13. https://doi.org/10. 1007/s11469-020-00264-6 
Karlsson, J., Persson, L. O., Sjöström, L., \& Sullivan, M. (2000). Psychometric properties and factor structure of the three-factor eating questionnaire (TFEQ) in obese men and women. Results from the Swedish obese subjects (SOS) study. International Journal of Obesity, 24, 1715e1725.

Karr, T. M., Zunker, C., Thompson, R. A., Sherman, R. T., Erickson, A., Cao, L., Crosby, R. D., \& Mitchell, J. E. (2013). Moderators of the association between exercise identity and obligatory exercise among participants of an athletic event. Body Image, 10(1), 70-77. https://doi.org/10.1016/j.bodyim.2012.09.004

Kerr, J. H., Lindner, K. J., \& Blaydon, M. (2007). Exercise dependence. Routledge.

Kolnes, L. J., \& Rodriguez-Morales, L. (2016). The meaning of compulsive exercise in women with anorexia nervosa: An interpretative phenomenological analysis. Mental Health and Physical Activity, 10, 48-61. https://doi.org/10.1016/j.mhpa.2015.12.002

Kostrzewa, E., Eijkemans, M. J., \& Kas, M. J. (2013). The expression of excessive exercise co-segregates with the risk of developing an eating disorder in women. Psychiatry Research, 210(3), 1123-1128. https://doi. org/10.1016/j.psychres.2013.08.050

Le Grange, D., \& Eisler, I. (1993). The link between anorexia nervosa and excessive exercise: A review. European Eating Disorders Review, 1(2), 100-119. https://doi.org/10.1002/erv.2400010205

Levit, M., Weinstein, A., Weinstein, Y., Tzur-Bitan, D., \& Weinstein, A. (2018). A study on the relationship between exercise addiction, abnormal eating attitudes, anxiety and depression among athletes in Israel. Journal of Behavioral Addictions, 7(3), 800-805. https://doi.org/10.1556/2006.7.2018.83

Lichtenstein, M. B., Hinze, C. J., Emborg, B., Thomsen, F., \& Hemmingsen, S. D. (2017). Compulsive exercise: Links, risks and challenges faced. Psychology Research and Behavior Management, 10, 85-95. https://doi. org/10.2147/PRBM.S113093

Lichtenstein, M. B., Griffiths, M. D., Hemmingsen, S. D., \& Støving, R. K. (2018). Exercise addiction in adolescents and emerging adults - Validation of a youth version of the Exercise Addiction Inventory. Journal of Behavioral Addictions, 7(1), 117-125. https://doi.org/10.1556/2006.7.2018.01

Magee, C. A., Buchanan, I., \& Barrie, L. (2016). Profiles of exercise dependence symptoms in Ironman participants. Psychology of Sport and Exercise, 24, 48-55. https://doi.org/10.1016/j.psychsport.2016.01.005

Marques, A., Peralta, M., Sarmento, H., Loureiro, V., Gouveia, É. R., \& de Matos, M. G. (2019). Prevalence of risk for exercise dependence: A systematic review. Sports Medicine, 49(2), 319-330. https://doi.org/10. 1007/s40279-018-1011-4

McCabe, M., \& Ricciardelli, L. (2004). A longitudinal study of pubertal timing and extreme body change behaviors among adolescent boys and girls. Adolescence, 3(153), 145-166.

Melissa, R., Lama, M., Laurence, K., Sylvie, B., Jeanne, D., Odile, V., \& Nathalie, G. (2020). Physical activity in eating disorders: A systematic review. Nutrients, 12(1), 183. https://doi.org/10.3390/nu12010183

Meyer, C., \& Taranis, L. (2011). Exercise in the eating disorders: Terms and definitions. European Eating Disorders Review, 19(3), 169-173. https://doi.org/10.1002/erv.1121

Meyer, C., Taranis, L., Goodwin, H., \& Haycraft, E. (2011). Compulsive exercise and eating disorders. European Eating Disorders Review, 19(3), 174-189. https://doi.org/10.1002/erv.1122

Moher, D., Liberati, A., Tetzlaff, J., \& Altman, D. G. (2009). The PRISMA Group. Preferred reporting items for systematic reviews and meta-analyses: The PRISMA statement. Annals of Internal Medicine, 151(4), $264-269$.

Moher, D., Shamseer, L., Clarke, M., Ghersi, D., Liberati, A., Petticrew, M., \& Stewart, L. A. (2015). Preferred reporting items for systematic review and meta-analysis protocols (PRISMA-P) 2015 statement. Systematic Reviews, 4(1), 1-9. https://doi.org/10.1186/2046-4053-4-1

Mond, J. M., Hay, P. J., Rodgers, B., \& Owen, C. (2006). An update on the definition of "excessive exercise" in eating disorders research. International Journal of Eating Disorders, 39(2), 147-153. https://doi.org/10. 1002/eat.20214

Nogueira, A., Molinero, O., Salguero, A., \& Márquez, S. (2018). Exercise addiction in practitioners of endurance sports: A literature review. Frontiers in Psychology, 9, 1484. https://doi.org/10.3389/fpsyg.2018.01484

Noles, S. W., Cash, T. F., \& Winstead, B. A. (1985). Body image, physical attractiveness, and depression. Journal of Consulting and Clinical Psychology, 53, 88-94.

Ogden, J., Veale, D. M. W., \& Summers, Z. (1997). The development and validation of the Exercise Dependence Questionnaire. Addiction Research, 5, 343-356.

Pasman, L., \& Thompson, J. K. (1988). Body image and eating disturbance in obligatory runners, obligatory weightlifters, and sedentary individuals. International Journal of Eating Disorders, 7(6), 759-769.

Petit, A., \& Lejoyeux, M. (2013). Exercise addiction. Revue Medicale de Liege, 68(5-6), 331-339.

Piacentino, D., Kotzalidis, G. D., Longo, L., Pavan, A., Stivali, L., Stivali, G., et al. (2017). Body image and eating disorders are common among professional and amateur athletes using performance and image enhancing drugs: A cross-sectional study. Journal of Psychoactive Drugs, 49(5), 373-384. https://doi.org/ $10.1080 / 02791072.2017 .1359708$ 
Plateau, C. R., Shanmugam, V., Duckham, R. L., Goodwin, H., Jowett, S., Brooke-Wavell, K. S., et al. (2014). Use of the compulsive exercise test with athletes: Norms and links with eating psychopathology. Journal of Applied Sport Psychology, 26(3), 287-301. https://doi.org/10.1080/10413200.2013.867911

Plateau, C. R., Arcelus, J., \& Meyer, C. (2017). Detecting eating psychopathology in female athletes by asking about exercise: Use of the Compulsive Exercise Test. European Eating Disorders Review, 25(6), 618-624. https://doi.org/10.1002/erv.2561

Pritchard, M. E., Rush, P., \& Milligan, B. (2007). Risk factors for disordered eating in high school and college athletes. Athletic Insight, 9(3), 33.

Reardon, C. L., \& Factor, R. M. (2010). Sport psychiatry. Sports Medicine, 40(11), 961-980. https://doi.org/10. 2165/11536580-000000000-00000

Reche, C., \& Gómez, M. (2014). Dependencia al ejercicio físico y trastornos de la conducta alimentaria. Apuntes de Psicología, 32(1), 25-32.

Sauchelli, S., Arcelus, J., Granero, R., Jiménez-Murcia, S., Agüera, Z., Pino-Gutiérrez, D., \& Fernández-Aranda, F. (2016). Dimensions of compulsive exercise across eating disorder diagnostic subtypes and the validation of the Spanish version of the Compulsive Exercise Test. Frontiers in Psychology, 7, 1852. https://doi.org/10. 3389/fpsyg.2016.01852

Slay, H. A., Hayaki, J., Napolitano, M. A., \& Brownell, K. D. (1998). Motivations for running and eating attitudes in obligatory versus nonobligatory runners. International Journal of Eating Disorders, 23(3), 267275 .

Szabo, A. (2009). Addiction to exercise: A symptom or a disorder? In C. H. Chan (Ed.), Handbook of sports psychology. Sports and Athletics Preparation Performance and Psychology (pp. 123-170). Nova Science Publishers.

Szabo, A. (2010). Exercise addiction and eating disorders. In A. Szabo (Ed.), Addiction to exercise: a symptom or a disorder? (pp. 51-61). Nova Science Publishers.

Szabo, A., \& Egorov, A. Y. (2015). Exercise addiction. In A. M. Lane (Ed.), Sport and Exercise Psychology (2nd ed., pp. 190-220). Routledge.

Szabo, A., Griffiths, M. D., Marcos, R. D. L. V., Mervó, B., \& Demetrovics, Z. (2015). Focus: Addiction: Methodological and conceptual limitations in exercise addiction research. The Yale Journal of Biology and Medicine, 88(3), 303-308.

Szabo, A., Griffiths, M. D., \& Demetrovics, Z. (2016). Exercise addiction. In V. Preedy (Ed.), The neuropathology of drug addictions and substance misuse, Vol. 3 (pp. 984-992). Academic Press.

Szabo, A., Demetrovics, Z., \& Griffiths, M. D. (2018). Morbid exercise behavior: Addiction or psychological escape? In H. Budde \& M. Wegner (Eds.), The exercise effect on mental health: Neurobiological mechanisms (pp. 277-311). Taylor and Francis.

Taranis, L., Touyz, S., \& Meyer, C. (2011). Disordered eating and exercise: Development and preliminary validation of the Compulsive Exercise Test (CET). European Eating Disorders Review, 19(3), 256-268. https://doi.org/10.1002/erv.1108

Teixeira, P. C., da Costa, R. F., Matsudo, S. M., \& Cordas, T. A. (2009). Physical exercises in patients with eating disorders. Revista de Psiquiatría Clínica, 36(4), 138-145.

Thompson, J. K., van den Berg, P., Roehrig, M., Guarda, A. S., \& Heinberg, L. J. (2004). The Sociocultural Attitudes Toward Appearance Scale-3 (SATAQ-3): Development and validation. International Journal of Eating Disorders, 35(3), 293-304.

Torstveit, M. K., Fahrenholtz, I. L., Lichtenstein, M. B., Stenqvist, T. B., \& Melin, A. K. (2019). Exercise dependence, eating disorder symptoms and biomarkers of Relative Energy Deficiency in Sports (RED-S) among male endurance athletes. BMJ Open Sport \& Exercise Medicine, 5(1), e000439. https://doi.org/10. 1136/bmjsem-2018-000439

Trott, M., Jackson, S. E., Firth, J., Fisher, A., Johnstone, J., Mistry, A., Stubbs, B., \& Smith, L. (2020a). Exercise addiction prevalence and correlates in the absence of eating disorder symptomology: A systematic review and meta-analysis. Journal of Addiction Medicine, 14(6), e321-e329. https://doi.org/10.1097/ADM. 0000000000000664

Trott, M., Jackson, S. E., Firth, J., Jacob, L., Grabovac, I., Mistry, A., Stubbs, B., \& Smith, L. (2020b). A comparative meta-analysis of the prevalence of exercise addiction in adults with and without indicated eating disorders. Eating and Weight Disorders-Studies on Anorexia, Bulimia and Obesity., 26, 37-46. https://doi. org/10.1007/s40519-019-00842-1

Turton, R., Goodwin, H., \& Meyer, C. (2017). Athletic identity, compulsive exercise and eating psychopathology in long-distance runners. Eating Behaviors, 26, 129-132. https://doi.org/10.1016/j.eatbeh.2017.03.001

Warner, R., \& Griffiths, M. D. (2006). A qualitative thematic analysis of exercise addiction: An exploratory study. International Journal of Mental Health and Addiction, 4(1), 13-26. https://doi.org/10.1007/s11469006-9000-5 
Weinstein, A., \& Weinstein, Y. (2014). Exercise addiction-diagnosis, bio-psychological mechanisms and treatment issues. Current Pharmaceutical Design, 20(25), 4062-4069. https://doi.org/10.2174/ 13816128113199990614

Yates, A. (1991). Compulsive exercise and the eating disorders. Brunner/Mazel.

Yates, A., Leehey, K., \& Shisslak, C. M. (1983). Running-An analogue of anorexia? New England Journal of Medicine, 308(5), 251-255. https://doi.org/10.1056/NEJM198302033080504

Zeeck, A., Schlegel, S., Giel, K. E., Junne, F., Kopp, C., Joos, A., Davis, C., \& Hartmann, A. (2017). Validation of the German version of the commitment to exercise scale. Psychopathology, 50(2), 146-156. https://doi. org/10.1159/000455929

Publisher's Note Springer Nature remains neutral with regard to jurisdictional claims in published maps and institutional affiliations.

\section{Affiliations}

\section{Débora Godoy-Izquierdo ${ }^{1,2}$ • María J. Ramírez ${ }^{2}$ - Isabel Díaz ${ }^{3}$. Clara López-Mora ${ }^{4}$}

1 Department of Personality, Assessment \& Psychological Treatment, Faculty of Psychology, University of Granada, Granada, Spain

2 Research Group "Health Psychology \& Behavioral Medicine” CTS267, University of Granada, Granada, Spain

3 Gimbernat-Cantabria University Schools, University of Cantabria, Santander, Spain

4 Seneca Foundation \& Dep. Human Development and Family Science, College of Human Environmental Sciences, University of Missouri, Columbia, MO, USA 